\title{
Mass-conserving subglacial hydrology in the Parallel Ice Sheet Model version 0.6
}

\author{
E. Bueler ${ }^{1}$ and W. van Pelt ${ }^{2, *}$ \\ ${ }^{1}$ Department of Mathematics and Statistics and Geophysical Institute, University of Alaska Fairbanks, USA \\ ${ }^{2}$ Institute for Marine and Atmospheric Research Utrecht, the Netherlands \\ * current address: Department of Earth Sciences, Uppsala University, Sweden \\ Correspondence to: Ed Bueler (elbueler@alaska.edu)
}

Received: 20 June 2014 - Published in Geosci. Model Dev. Discuss.: 29 July 2014

Revised: 22 April 2015 - Accepted: 23 April 2015 - Published: 2 June 2015

\begin{abstract}
We describe and test a two-horizontal-dimension subglacial hydrology model which combines till with a distributed system of water-filled, linked cavities which open through sliding and close through ice creep. The addition of this sub-model to the Parallel Ice Sheet Model (PISM) accomplishes three specific goals: (a) conservation of the mass of water, (b) simulation of spatially and temporally variable basal shear stress from physical mechanisms based on a minimal number of free parameters, and (c) convergence under grid refinement. The model is a common generalization of four others: (i) the undrained plastic bed model of Tulaczyk et al. (2000b), (ii) a standard "routing" model used for identifying locations of subglacial lakes, (iii) the lumped englacial-subglacial model of Bartholomaus et al. (2011), and (iv) the elliptic-pressure-equation model of Schoof et al. (2012). We preserve physical bounds on the pressure. In steady state a functional relationship between water amount and pressure emerges. We construct an exact solution of the coupled, steady equations and use it for verification of our explicit time stepping, parallel numerical implementation. We demonstrate the model at scale by 5 year simulations of the entire Greenland ice sheet at $2 \mathrm{~km}$ horizontal resolution, with one million nodes in the hydrology grid.
\end{abstract}

\section{Introduction}

Any continuum-physics-based dynamical model of the liquid water underneath and within a glacier or ice sheet has at least these two elements: the mass of the water is conserved and the water flows from high to low values of the mod- eled hydraulic potential. Beyond that there are many variations considered in the literature. Modeled aquifer geometry might be a system of linked cavities (Kamb, 1987), conduits (Nye, 1976), or a sheet (Creyts and Schoof, 2009). Geometry evolution processes might include the opening of cavities by sliding of the overlying ice past bedrock bumps (Schoof, 2005), the creation of cavities by interaction of the ice with deformable sediment (Schoof, 2007), closure of cavities and conduits by creep (Hewitt, 2011), or melt on the walls of cavities and conduits which causes them to open (Clarke, 2005). Water could move in a macro-porous englacial system (Bartholomaus et al., 2011) or it could be stored in a porous till (Tulaczyk et al., 2000a).

Models have combined subsets of these different morphologies and processes (Flowers and Clarke, 2002a; Hewitt, 2013; Hoffman and Price, 2014; Van der Wel et al., 2013; Werder et al., 2013; de Fleurian et al., 2014). However, the completeness of the modeled processes must be balanced against the number of uncertain model parameters and the ultimate availability of observations with which to constrain them.

This paper describes a carefully selected model for a distributed system of linked subglacial cavities, with additional storage of water in the pore spaces of subglacial till. Water in excess of the capacity of the till passes into the distributed transport system. In this sense the model could be called a "drained-and-conserved" extension of the "undrained" plastic bed model of Tulaczyk et al. (2000b).

The cavities in our modeled distributed system open by sliding of the ice over bedrock roughness and close by ice creep. These two physical processes combine to determine 
the relationship between water amount and pressure. Pressure is thereby determined non-locally over each connected component of the hydrological system. No functional relation between subglacial water amount and pressure is assumed (compare Flowers and Clarke, 2002a). The pressure solves an equation which is a parabolic regularization of the distributed pressure equation given in elliptic variational inequality form by Schoof et al. (2012).

In cases where boreholes have actually been drilled to the ice base, till is often observed (Hooke et al., 1997; Tulaczyk et al., 2000a; Truffer et al., 2000; Truffer and Harrison, 2006). Laboratory experiments on the rheology of till (Kamb, 1991; Hooke et al., 1997; Tulaczyk et al., 2000a; Truffer et al., 2001) generally conclude that its deformation is well approximated by a Mohr-Coulomb relation (Schoof, 2006b). For this reason we adopt a compressible-Coulombplastic till model when determining the effective pressure on the till as a function of the amount of water stored in it (Tulaczyk et al., 2000a). Existing models which combine till and a mass-conservation equation for the subglacial water are rather different from ours, as they either have only onehorizontal dimension (Van der Wel et al., 2013) or have a pressure equation which directly ties water pressure to water amount, which generates a porous-medium equation form (Flowers and Clarke, 2002a; de Fleurian et al., 2014).

The major goals here are to implement, verify, and demonstrate this two-dimensional subglacial hydrology model. The model is applicable at a wide variety of spatial and temporal scales but it has relatively few parameters. It is parallelized and it exhibits convergence of solutions under grid refinement. It is a sub-model of a comprehensive threedimensional ice sheet model, the open-source Parallel Ice Sheet Model (PISM; http://pism-docs.org); the sub-model can be added to any PISM run by a simple run-time option.

Channelized subglacial flow is widely assumed to occur in Greenland, based on borehole and moulin evidence (Andrews et al., 2014, for example). This important physical process for subglacial hydrologic transport is not captured by our model because conduits are not modeled. Existing theories of conduits apparently require their locations to be fixed a priori (Schoof, 2010b; Hewitt, 2013; Werder et al., 2013). Such lattice models have no known continuum limit in the map plane. By contrast with conduits, linked-cavity models do not put the cavities at the nodes of a pre-determined lattice, exactly because the continuum limit of such a lattice model is known (Hewitt, 2011), namely as a partial differential equation (PDE; Eq. 13 in the current paper). Regarding lattice models, because all PISM usage involves a run-time determination of grid resolution, all parameters must have grid-spacing-independent meaning. Lattice or other inputgrid-based models are therefore not acceptable as components of PISM.

Wall melt in the linked-cavity system, which is believed to be small (Kamb, 1987), is not added into the massconservation equation in our model. (It can be calculated diagnostically from the modeled flux and hydraulic gradient, however.) If included in mass conservation, the addition of wall melt can generate an unstable distributed system (Walder, 1982), though such a system can be stabilized to some degree by bedrock bumps (Creyts and Schoof, 2009).

The structure of the paper is as follows: Sect. 2 considers basic physical principles, culminating with a fundamental advection-diffusion form of the mass-conservation equation. Section 3 reviews what is known about till mechanical properties, water in till pore spaces, and shear stress at the base of a glacier. In Sect. 4 we compare "closures" which directly or indirectly determine the subglacial water pressure. Based on all these elements, in Sect. 5 we summarize the new model and the role of its major fields. In this section we show how the model extends several published models, we note properties of its steady states (see also Appendix A), and we compute a nearly exact steady solution in the map plane, a useful tool for verification. In Sect. 6 we present the numerical schemes, with particular attention to time-step restrictions and the treatment of advection, and we document the PISM options and parameters seen by users. Section 7 shows numerical results from the model, starting with convergence under grid refinement in the verification case. We then demonstrate the model in 5 year runs on a $2 \mathrm{~km}$ grid covering the entire Greenland ice sheet.

\section{Elements of subglacial hydrology}

\subsection{Mass conservation}

We assume that liquid water is of constant density $\rho_{\mathrm{w}}$; see Table 1 for constants. Thus, the thickness of the layer of laterally moving water, denoted by $W(t, x, y)$, determines its mass; see Table 2 for variable names and meanings. In addition there is liquid water stored locally in the pore spaces of till (Tulaczyk et al., 2000b) which is also described by an effective thickness $W_{\text {til }}(t, x, y)$. Such thicknesses are only meaningful compared to observations if they are regarded as averages over a horizontal scale of meters to hundreds of meters (Flowers and Clarke, 2002a). Thus, the total effective thickness of the water at map-plane location $(x, y)$ and time $t$ is $W+W_{\text {til }}$. This sum is the conserved quantity in our model. In two map-plane dimensions the mass-conservation equation is (compare Clarke, 2005)

$$
\frac{\partial W}{\partial t}+\frac{\partial W_{\mathrm{til}}}{\partial t}+\nabla \cdot \boldsymbol{q}=\frac{m}{\rho_{\mathrm{w}}}
$$

where $\nabla \cdot=\frac{\partial}{\partial x}+\frac{\partial}{\partial y}$ denotes divergence, $\boldsymbol{q}$ is the vector water flux $\left(\mathrm{m}^{2} \mathrm{~s}^{-1}\right)$, and $m$ is the total input to the subglacial hydrology $\left(\mathrm{kg} \mathrm{m}^{-2} \mathrm{~s}^{-1}\right)$. Note that the water flux $\boldsymbol{q}$ is concentrated within the two-dimensional subglacial layer.

The water source $m$ in Eq. (1) includes both melt on the base of the glacier and drainage to the bed from the glacier surface. In portions of ice sheets with cold surface conditions, 
Table 1. Physical constants and model parameters. All values are configurable in PISM; see Table 3.

\begin{tabular}{|c|c|c|c|}
\hline Name & Default & Units & Description \\
\hline$A$ & $3.1689 \times 10^{-24}$ & $\mathrm{~Pa}^{-3} \mathrm{~s}^{-1}$ & ice softness (Huybrechts et al., 1996) \\
\hline$\alpha$ & $\frac{5}{4}$ & & power in flux formula (Schoof et al., 2012) \\
\hline$\beta$ & $\frac{3}{2}$ & & power in flux formula (Schoof et al., 2012) \\
\hline$c_{0}$ & 0 & $\mathrm{~Pa}$ & till cohesion (Tulaczyk et al., 2000a) \\
\hline$c_{1}$ & 0.5 & $\mathrm{~m}^{-1}$ & cavitation coefficient (Schoof et al., 2012) \\
\hline$c_{2}$ & 0.04 & & creep closure coefficient \\
\hline$C_{\mathrm{c}}$ & 0.12 & & till compressibility (Tulaczyk et al., 2000a) \\
\hline$C_{\mathrm{d}}$ & 0.001 & $\mathrm{ma}^{-1}$ & background till drainage rate \\
\hline$\delta$ & 0.02 & & $N_{\text {til }}$ lower bound, as fraction of overburden pressure \\
\hline$e_{0}$ & 0.69 & & reference void ratio at $N_{0}$ (Tulaczyk et al., 2000a) \\
\hline$\phi_{0}$ & 0.01 & & notional (regularizing) englacial porosity \\
\hline$g$ & 9.81 & $\mathrm{~m} \mathrm{~s}^{-2}$ & acceleration of gravity \\
\hline$k$ & 0.001 & $\mathrm{~m}^{2 \beta-\alpha} \mathrm{s}^{2 \beta-3} \mathrm{~kg}^{1-\beta}$ & conductivity coefficient (Schoof et al., 2012) \\
\hline$N_{0}$ & 1000 & $\mathrm{~Pa}$ & reference effective pressure (Tulaczyk et al., 2000a) \\
\hline$\rho_{i}$ & 910 & $\mathrm{~kg} \mathrm{~m}^{-3}$ & ice density (Greve and Blatter, 2009) \\
\hline$\rho_{\mathrm{W}}$ & 1000 & $\mathrm{~kg} \mathrm{~m}^{-3}$ & fresh water density (Greve and Blatter, 2009) \\
\hline$W_{\mathrm{r}}$ & 0.1 & $\mathrm{~m}$ & roughness scale (Hewitt et al., 2012) \\
\hline$W_{\text {til }}^{\max }$ & 2 & $\mathrm{~m}$ & maximum water in till (Bueler and Brown, 2009) \\
\hline
\end{tabular}

Table 2. Functions used in the subglacial hydrology model (Eq. 32).

\begin{tabular}{|c|c|c|c|}
\hline Type & \multicolumn{3}{|c|}{ Description (symbol, units, meaning) } \\
\hline \multirow{3}{*}{ State } & $W$ & $\mathrm{~m}$ & transportable water thickness \\
\hline & $W_{\text {til }}$ & $\mathrm{m}$ & till-stored water thickness \\
\hline & $P$ & $\mathrm{~Pa}$ & transportable water pressure \\
\hline \multirow{5}{*}{ Input } & $b$ & $\mathrm{~m}$ & bedrock elevation \\
\hline & $\varphi$ & & till friction angle \\
\hline & $H$ & $\mathrm{~m}$ & ice thickness \\
\hline & $m$ & $\mathrm{~kg} \mathrm{~m}^{-2} \mathrm{~s}^{-1}$ & total melt water input \\
\hline & $\left|\boldsymbol{v}_{\mathrm{b}}\right|$ & $\mathrm{ms}^{-1}$ & ice sliding speed \\
\hline \multirow{2}{*}{ Output } & $N_{\text {til }}$ & $\mathrm{Pa}$ & till effective pressure \\
\hline & $\tau_{\mathrm{c}}$ & $\mathrm{Pa}$ & till yield stress \\
\hline
\end{tabular}

such as Antarctica and the interior of Greenland, the basal melt rate part of $m$ is dominated by the energy balance at the base of the ice (Aschwanden et al., 2012). The Greenland results in Sect. 7 use only that basal melt for $m$. Drainage from the surface has also been added to $m$ in applications of our model (Van Pelt, 2013), but modeling such drainage is outside the scope of this paper.

\subsection{Hydraulic potential and water pressure}

The hydraulic potential $\psi(t, x, y)$ combines the pressure $P(t, x, y)$ of the transportable subglacial water and the gravitational potential of the top of the water layer (Goeller et al., 2013; Hewitt et al., 2012),

$\psi=P+\rho_{\mathrm{w}} g(b+W)$.
Here $z=b(x, y)$ is the bedrock elevation.

We have added the term " $\rho_{\mathrm{w}} g W$ " to the standard hydraulic potential formula $\psi=P+\rho_{\mathrm{w}} g b$ (Clarke, 2005; Shreve, 1972) because differences in the potential at the top of the subglacial water layer determine the driving potential gradient for a fluid layer. When the water depth becomes substantial $(W \gg 1 \mathrm{~m})$, as it would be in a subglacial lake, this term keeps the modeled lakes from being singularities of the water thickness field (compare Le Brocq et al., 2009).

Ice is a viscous fluid which has a stress field of its own. The basal value of the downward normal stress, called the overburden pressure, is denoted by $P_{\mathrm{o}}$. We accept the shallow approximation that this stress is hydrostatic (Greve and Blatter, 2009):

$P_{\mathrm{o}}=\rho_{i} g H$,

where $H$ is the ice thickness.

Overpressure $P>P_{\mathrm{o}}$ has been observed in ice sheets, but only for short durations (Das et al., 2008). In our model and others (Schoof et al., 2012), however, because the condition $P>P_{\mathrm{O}}$ is presumed to cause the ice to lift and thus reduce the pressure back to overburden $P=P_{\mathrm{o}}$, the pressure solution is subject to inequalities

$0 \leq P \leq P_{0}$.

\subsection{Darcy flow}

Subglacial water flows from high to low hydraulic potential. The simplest expression of this is a Darcy flux model for a water sheet:

$\boldsymbol{q}=-K W \nabla \psi$, 
where the hydraulic conductivity $K$ is a constant (Clarke, 2005). More generally Schoof et al. (2012) suggests a powerlaw form

$\boldsymbol{q}=-k W^{\alpha}|\nabla \psi|^{\beta-2} \nabla \psi$

for $\alpha \geq 1, \beta>1$, and a coefficient $k>0$ with units that depend on $\alpha$ and $\beta$ (see Table 1). Clarke (2005) suggests $\alpha=1$ and $\beta=2$, to give Eq. (5) above, Creyts and Schoof (2009) use $\alpha=3 / 2$ and $\beta=3 / 2$, Hewitt $(2011,2013)$ uses $\alpha=3$ and $\beta=2$, and Hewitt et al. (2012) suggest $\alpha=5 / 4$ and $\beta=3 / 2$. The current paper generally implements Eq. (6) but uses the Clarke (2005) and Hewitt et al. (2012) exponents in an exact solution and in numerical experiments, respectively. We call $K=k W^{\alpha-1}|\nabla \psi|^{\beta-2}$ the effective hydraulic conductivity, so that Eq. (5) applies formally throughout.

\subsection{Advection-diffusion decomposition}

Combining Eqs. (2) and (6), and separating the term proportional to $\nabla W$, we get the flux expression

$$
\begin{aligned}
\boldsymbol{q}= & -k W^{\alpha}|\nabla \psi|^{\beta-2} \nabla\left(P+\rho_{\mathrm{w}} g b\right) \\
& -\rho_{\mathrm{w}} g k W^{\alpha}|\nabla \psi|^{\beta-2} \nabla W,
\end{aligned}
$$

which suggests a mix of mechanisms. If $P$ scales with the overburden pressure $P_{\mathrm{o}}$, and if $|\nabla(H+b)| \gg|\nabla W|$, then the first flux term in Eq. (7) will dominate. In any case, the second term with $\nabla W$ acts diffusively in the mass conservation Eq. (1). We will see that in near-steady-state circumstances where there is significant sliding, the first term with $\nabla P$ is also significantly diffusive in the mass-conservation equation (Sect. 5.3). In conditions far from steady state, however, the direction of $\nabla P$ is presumably different from the direction $\nabla W$.

We will construct our numerical scheme based on decomposition Eq. (7). To simplify the expression slightly, the small thickness approximation $W \approx 0$ is made inside the absolute value signs in Eq. (7), namely,

$|\nabla \psi| \approx\left|\nabla\left(P+\rho_{\mathrm{w}} g b\right)\right|$.

This simplification, which makes no change in the $\beta=2$ case (see Sect. 2.3), lets us redefine the effective hydraulic conductivity as

$$
K=k W^{\alpha-1}\left|\nabla\left(P+\rho_{\mathrm{w}} g b\right)\right|^{\beta-2} .
$$

In terms of $K$ we define a velocity field and a diffusivity coefficient:

$$
\boldsymbol{V}=-K \nabla\left(P+\rho_{\mathrm{w}} g b\right), \quad D=\rho_{\mathrm{w}} g K W,
$$

so that Eq. (7) is a clean advection-diffusion decomposition:

$\boldsymbol{q}=\boldsymbol{V} W-D \nabla W$.
From Eqs. (1) and (11) we now have an advectiondiffusion-production equation for the evolution of the conserved water amount $W+W_{t i l}$ :

$\frac{\partial W}{\partial t}+\frac{\partial W_{\mathrm{til}}}{\partial t}=-\nabla \cdot(\boldsymbol{V} W)+\nabla \cdot(D \nabla W)+\frac{m}{\rho_{\mathrm{w}}}$.

There are distinct numerical approximations for the advection term $\nabla \cdot(\boldsymbol{V} W)$ and the diffusion term $\nabla \cdot(D \nabla W)$, with time-step restrictions of different magnitudes (Sect. 6). Equation (12) is often advection dominated in the sense that $|\boldsymbol{V} W| \gg|D \nabla W|$, and numerical schemes for advection and diffusion must be tested in combination (Sect. 7).

\subsection{Capacity of a linked-cavity distributed system}

The rate of change of the area-averaged thickness of the cavities in a distributed linked-cavity system is the difference of opening and closing rates (Hewitt, 2011). This thickness $Y$, also called "bed separation" (Bartholomaus et al., 2011), has the generic evolution equation

$\frac{\partial Y}{\partial t}=\mathcal{O}\left(\left|\boldsymbol{v}_{\mathrm{b}}\right|, Y\right)-\mathcal{C}(N, Y)$,

where $\boldsymbol{v}_{\mathrm{b}}$ is the ice base (sliding) velocity and $N=P_{\mathrm{o}}-P$ is the effective pressure on the cavity system. Denoting $X_{+}=$ $\max \{0, X\}$, we choose a non-negative opening term based on cavitation only:

$\mathcal{O}\left(\left|\boldsymbol{v}_{\mathrm{b}}\right|, Y\right)=c_{1}\left|\boldsymbol{v}_{\mathrm{b}}\right|\left(W_{\mathrm{r}}-Y\right)_{+}$.

Here $c_{1}$ is a scaling coefficient and $W_{\mathrm{r}}$ is a maximum roughness scale of the basal topography (Schoof et al., 2012); see Table 1 . The closing term models ice creep only (Hewitt, 2011; Schoof et al., 2012):

$\mathcal{C}(N, Y)=c_{2} A N^{3} Y$,

where $c_{2}$ is a scaling coefficient and $A$ is the softness of the ice. We have used Glen exponent $n=3$ for concreteness and simplicity. The closing term $\mathcal{C}$ in Eq. (15) is nonnegative because our modeled pressure $P$ satisfies the bounds $0 \leq P \leq P_{\mathrm{o}}$.

\section{Till hydrology and mechanics}

Till with pressurized liquid water in its pore spaces is expected to support much of the ice overburden. When present, such saturated till is central to the complicated relationship between the amount of subglacial water and the speed of sliding. Our model includes storage of subglacial water in till both because of its role in conserving the mass of liquid water and its role in determining basal shear stress.

We will assume throughout that liquid water or ice fills the pore spaces in the till, and that there are no air- or vapor-filled pore spaces. When $W_{\text {til }}=0$ in the model, the pore spaces 
in the till are regarded as filled with ice and the basal shear stress is correspondingly high. When $W_{\text {til }}$ attains sufficiently large values, however, the till is regarded as saturated with liquid, and a drop in effective pressure becomes possible (Sect. 3.2 below).

\subsection{Evolution of till-stored water layer thickness}

The water in till pore spaces is much less mobile than that in the linked-cavity system because of the very low hydraulic conductivity of till (Lingle and Brown, 1987; Truffer et al., 2001). Therefore, we choose an evolution equation for $W_{\text {til }}$ without horizontal transport for simplicity (Tulaczyk et al., 2000a), namely,

$$
\frac{\partial W_{\mathrm{til}}}{\partial t}=\frac{m}{\rho_{\mathrm{w}}}-C_{\mathrm{d}} .
$$

Here $C_{\mathrm{d}} \geq 0$ is a fixed rate that makes the till gradually drain in the absence of water input; we choose $C_{\mathrm{d}}=1 \mathrm{~mm} \mathrm{a}^{-1}$, which is small compared to typical values of $m / \rho_{\mathrm{w}}$. Refreeze is also allowed, as a negative value for $m$.

As in Bueler and Brown (2009), we constrain the layer thickness by

$0 \leq W_{\mathrm{til}} \leq W_{\mathrm{til}}^{\max }$

Any water in excess of the capacity of the till, i.e., $W_{\text {til }}^{\max }$, "overflows" the till and enters the transport system; it is conserved. Because the source term $m$ in Eq. (16), or the whole right side, can be negative, the lower bound in inequalities (17) must be actively enforced. The upper bound in inequalities (17) also relates to the effective pressure on the till, as we explain next.

\subsection{Effective pressure on the till}

Deformation of saturated till is well modeled by a plastic (Coulomb friction) or nearly plastic rheology (Hooke et al., 1997; Truffer et al., 2000; Tulaczyk et al., 2000a; Schoof, $2006 \mathrm{~b}$ ). Its yield stress $\tau_{\mathrm{c}}$ satisfies the Mohr-Coulomb relation:

$\tau_{\mathrm{c}}=c_{0}+(\tan \varphi) N_{\mathrm{til}}$,

where $c_{0}$ is the till cohesion, $\varphi$ is the till friction angle, and $N_{\text {til }}$ is the effective pressure of the overlying ice on the saturated till (Cuffey and Paterson, 2010). (Note that the effective pressure $N=P_{\mathrm{o}}-P$ used in Sect. 2.5 for modeling cavity closure is distinct from $N_{\text {til }}$ in Eq. (18). This distinction is again explained by the very low hydraulic conductivity of till.)

Let $e=V_{\mathrm{w}} / V_{\mathrm{s}}$ be the till void ratio, where $V_{\mathrm{w}}$ is the volume of water in the pore spaces and $V_{\mathrm{s}}$ is the volume of mineral solids (Tulaczyk et al., 2000a). From the standard theory of soil mechanics and from laboratory experiments on till (Hooke et al., 1997; Tulaczyk et al., 2000a), a linear relation exists between $e$ and the logarithm of $N_{\text {til }}$,

$e=e_{0}-C_{\mathrm{c}} \log _{10}\left(N_{\mathrm{til}} / N_{0}\right)$.

Figure 1a shows a graph of Eq. (19). Here $e_{0}$ is the void ratio at a reference effective pressure $N_{0}$, and $C_{\mathrm{c}}$ is the coefficient of compressibility of the till. Equivalently to Eq. (19), $N_{\text {til }}$ is an exponential function of $e$, namely, $N_{\mathrm{til}}=N_{0} 10^{\left(e_{0}-e\right) / C_{\mathrm{c}}}$ (Van der Wel et al., 2013, Eq. 15), so $N_{\text {til }}$ is nonzero for all finite values of $e$.

While Eq. (19) suggests that the effective pressure could be any positive number, in fact the area-averaged value of $N_{\text {til }}$ under ice sheets and glaciers has limits. It cannot exceed the overburden pressure for any sustained period. Furthermore, once the till is close to its maximum capacity then the excess water will be "drained" into a transport system. We suppose this occurs at a small, fixed fraction $\delta$ of the overburden pressure. Thus, we assume the bounds

$\delta P_{\mathrm{o}} \leq N_{\mathrm{til}} \leq P_{\mathrm{o}}$,

where $\delta=0.02$ in the experiments in this paper.

The void ratio $e$ and the effective water layer thickness $W_{\text {til }}$ are describing the same thing, namely, the amount of liquid water in the till. In fact, if $\Delta x, \Delta y$ are the horizontal dimensions of a rectangular patch of till with (mineral-portion) thickness $\eta$ then $V_{\mathrm{w}}=W_{\text {til }} \Delta x \Delta y$ and $V_{\mathrm{s}}=\eta \Delta x \Delta y$. Thus,

$e=\frac{W_{\mathrm{til}}}{\eta}$.

On the other hand, we specify a maximum $W_{\text {til }}^{\max }$ on the water layer thickness, in the bounds (17). The minimum $N_{\mathrm{til}}=\delta P_{\mathrm{o}}$ of the effective pressure occurs at maximum values of void ratio $e$ and effective thickness $W_{\mathrm{til}}$, so Eqs. (19) and (21) allow us to express the solid-till thickness $\eta$ in terms of our preferred parameters $W_{\mathrm{til}}^{\max }, \delta, e_{0}, N_{0}$, and $C_{\mathrm{c}}$ :

$\eta=\frac{W_{\mathrm{til}}^{\max }}{e_{0}-C_{\mathrm{c}} \log _{10}\left(\frac{\delta P_{\mathrm{o}}}{N_{0}}\right)}$.

From Eqs. (19), (21), and (22), the effective pressure $N_{\text {til }}$ can now be written as the following function of $W_{\text {til }}$ :

$\hat{N}_{\mathrm{til}}=N_{0}\left(\frac{\delta P_{\mathrm{o}}}{N_{0}}\right)^{s} 10^{\left(\frac{e_{0}}{C_{\mathrm{c}}}\right)(1-s)}$,

where $s=W_{\mathrm{til}} / W_{\mathrm{til}}^{\max }$. However, as noted above, $N_{\mathrm{til}}$ is bounded:

$N_{\text {til }}=\min \left\{P_{\mathrm{o}}, \hat{N}_{\mathrm{til}}\right\}$.

This function is shown in Fig. 1b.

It follows from Eqs. (18), (23), and (24) that the yield stress $\tau_{\mathrm{c}}$ is determined by the layer thickness $W_{\mathrm{til}}$. Regarding the parameters in this relation: 

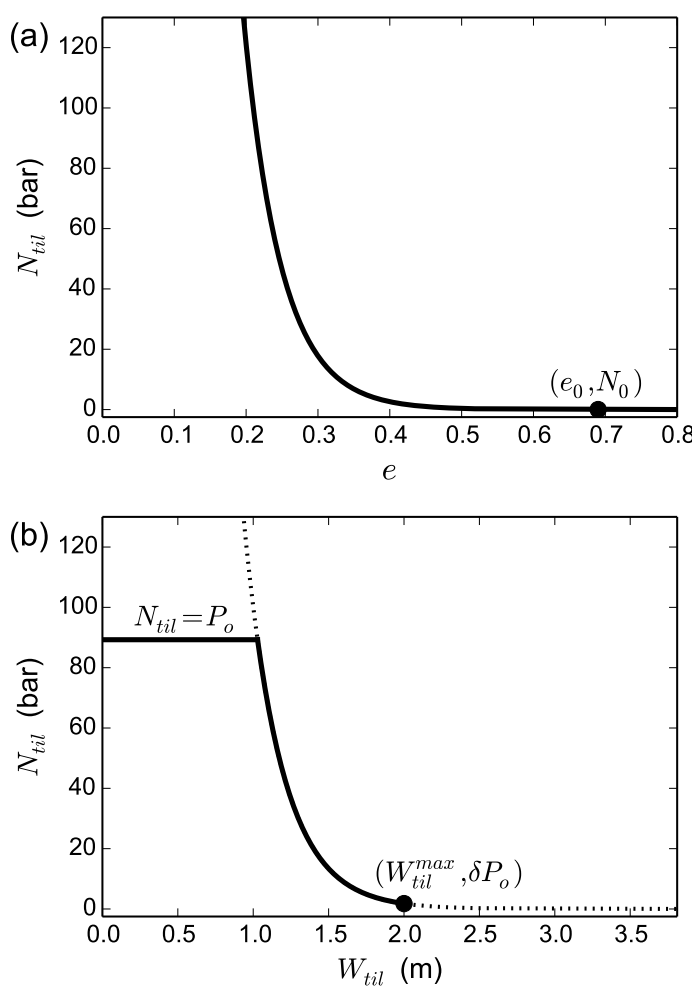

Figure 1. (a) Equation (19) determines the effective pressure $N_{\text {til }}$ as a function of the void ratio $e$; reference values $e_{0}, N_{0}$ are indicated. (b) The same curve, but with $N_{\text {til }}$ as a function of $W_{\text {til }}$, with bounds above by overburden pressure $P_{\mathrm{o}}$ and below by a fixed fraction $\delta$ of $P_{\mathrm{o}}$; the solid curve is used in our model. The case shown has 1000 meters ice thickness.

i. Experiments on till suggest small values for cohesion $c_{0}$ in Eq. (18), $0 \leq c_{0} \lesssim 1 \mathrm{kPa}$ (Tulaczyk et al., 2000a), and we choose $c_{0}=0$ for concreteness.

ii. Measured till friction angles $\varphi$ are in a $18-40^{\circ}$ range (Cuffey and Paterson, 2010). Simulations of the whole Antarctic (Martin et al., 2011) and Greenlandic (Aschwanden et al., 2013) ice sheets have been based on a hypothesis that the till friction angle $\varphi$ depends on bed elevation so as to model the submarine history of low-elevation sediments.

iii. The ratio $e_{0} / C_{\mathrm{c}}$ can be determined by laboratory experiments on till samples (e.g., Hooke et al., 1997; Tulaczyk et al., 2000a). Values for the dimensionless constants $e_{0}$ and $C_{\mathrm{c}}$ used here (Table 1) are from till samples from ice stream B in Antarctica (Tulaczyk et al., 2000a), and they give $e_{0} / C_{\mathrm{c}}=5.75$ in Eq. (23).

iv. The till capacity parameter $W_{\text {til }}^{\max }$ could be set in a location-dependent manner from in situ (Tulaczyk et al., 2000a) or seismic reflection (Rooney et al., 1987) evidence, but for simplicity we set it to a constant $2 \mathrm{~m}$.

\subsection{Sliding law}

Observe that the ice sliding velocity $\boldsymbol{v}_{\mathrm{b}}$ is an input into the subglacial hydrology model we are building, because of Eq. (14). On the other hand, the yield stress $\tau_{\mathrm{c}}$ is an output of the till-related part of the hydrology model (Sect. 3.2). In an ice dynamics model like PISM, $\boldsymbol{v}_{\mathrm{b}}$ is determined by solving a stress balance in which the vector basal shear stress $\boldsymbol{\tau}_{\mathrm{b}}$ appears either as a boundary condition (Schoof, 2010a) or as a term in a vertically integrated balance (Schoof, 2006a; Bueler and Brown, 2009). In PISM, $\tau_{\mathrm{c}}$ and $\boldsymbol{v}_{\mathrm{b}}$ combine to determine $\boldsymbol{\tau}_{\mathrm{b}}$ through a sliding law

$\boldsymbol{\tau}_{\mathrm{b}}=-\tau_{\mathrm{c}} \frac{\boldsymbol{v}_{\mathrm{b}}}{\left|\boldsymbol{v}_{\mathrm{b}}\right|^{1-q} v_{0}^{q}}$,

where $0 \leq q \leq 1$ and $v_{0}$ is a threshold sliding speed (Aschwanden et al., 2013).

Power-law Eq. (25) generalizes, and includes as the case $q=0$, the purely plastic (Coulomb) relation $\boldsymbol{\tau}_{\mathrm{b}}=$ $-\tau_{\mathrm{c}} \boldsymbol{v}_{\mathrm{b}} /\left|\boldsymbol{v}_{\mathrm{b}}\right|$. At least in the $q \ll 1$ cases, under Eq. (25) the till "yields" and the magnitude of the basal shear stress becomes nearly independent of $\left|\boldsymbol{v}_{\mathrm{b}}\right|$, when $\left|\boldsymbol{v}_{\mathrm{b}}\right| \gg v_{0}$. Equation (25) could also be written in generic power-law form $\boldsymbol{\tau}_{\mathrm{b}}=-\beta\left|\boldsymbol{v}_{\mathrm{b}}\right|^{q-1} \boldsymbol{v}_{\mathrm{b}}$ with coefficient $\beta=\tau_{\mathrm{c}} / v_{0}^{q}$; in the linear case $q=1$ we have $\beta=\tau_{\mathrm{c}} / v_{0}$.

\section{Closures to determine pressure}

The evolution equations listed so far, namely, Eqs. (12), (13), and (16), can be simplified to three equations in the four major variables $W, W_{\text {til }}, Y$, and $P$. We do not yet know how to compute the water pressure $P$ or its rate of change $\partial P / \partial t$ given the other variables and data of the problem. A closure is needed.

\subsection{Simplified closures without cavity evolution}

We first consider two simple closures which appear in the literature but which do not use cavity evolution Eq. (13) or similar physics. We list them because the resulting simplified conservation equations emerge as reductions of our more complete theory. For simplicity we present them without till storage $\left(W_{\text {til }}^{\max }=0\right)$ and only in the constant conductivity case $(\alpha=1$ and $\beta=2)$.

Setting the pressure equal to the overburden pressure is the simplest closure (Le Brocq et al., 2009; Shreve, 1972):

$P=P_{\mathrm{o}}$.

This model is sometimes used for "routing" subglacial water under ice sheets so as to identify subglacial lake locations (Goeller, 2014; Livingstone et al., 2013; Siegert et al., 2007). Straightforward calculations using Eqs. (1), (6), and (26) show that the advection-diffusion form Eq. (12) has an 
ice-geometry-determined velocity $\widetilde{\boldsymbol{V}}$,

$$
\begin{aligned}
\frac{\partial W}{\partial t} & =-\nabla \cdot(\widetilde{\boldsymbol{V}} W)+\nabla \cdot\left(\rho_{\mathrm{w}} g k W \nabla W\right)+\frac{m}{\rho_{\mathrm{w}}}, \\
\widetilde{\boldsymbol{V}} & =-\rho_{\mathrm{w}} g k\left[\frac{\rho_{i}}{\rho_{\mathrm{w}}} \nabla H+\left(1-\frac{\rho_{i}}{\rho_{\mathrm{w}}}\right) \nabla b\right] .
\end{aligned}
$$

Because the approximation $W \ll H$ is usually accepted, so that the hydraulic potential is insensitive to the water layer thickness, i.e., $\psi=P_{\mathrm{o}}+\rho_{\mathrm{w}} g b$ (Le Brocq et al., 2009), the diffusion term in Eq. (27) is usually not included. With this common simplification, Eq. (27) becomes an advection equation with a source term. It therefore possesses characteristic curves, trajectories of the water flow or "pathways" (Livingstone et al., 2013), which are determined by ice sheet geometry. However, without the diffusion term, Eq. (27) exhibits continuum solutions with infinite water concentration at every location where the simplified potential $\psi=$ $P_{\mathrm{o}}+\rho_{\mathrm{w}} g b$ has a minimum. Applications therefore only compute the characteristic curves themselves. We prefer Eq. (27) as stated, with the diffusion term, because it is well posed for positive initial and boundary values on $W$ (compare Hewitt et al., 2012), so that numerical solutions can converge under sufficient grid refinement.

At an almost opposite extreme, our second simplified closure makes the water pressure a function of the amount of water. Specifically, Flowers and Clarke (2002a) proposed

$$
P_{\mathrm{FC}}(W)=P_{\mathrm{o}}\left(\frac{W}{W_{\text {crit }}}\right)^{\frac{7}{2}},
$$

where, for Trapridge glacier, Flowers and Clarke (2002b) used $W_{\text {crit }}=0.1 \mathrm{~m}$. Thus, no separate pressure evolution equation needs to be solved.

One concern with form Eq. (28) is that $P_{\mathrm{FC}}(W)$ can be arbitrarily larger than overburden pressure (Schoof et al., 2012). In any case, Eq. (28) is used in Eqs. (1) and (6) to yield a nonlinear diffusion which generalizes the porous-medium equation $\partial W / \partial t=\nabla^{2}\left(W^{\gamma}\right)$ (Vázquez, 2007). The main idea in such a nonlinear diffusion is that the direction of the flux is $-\nabla W$. However, a Darcy-type model $\boldsymbol{q} \sim-\nabla \psi$ like Eq. (6) normally gives flux directions different from $-\nabla W$ in many cases, especially in rapidly evolving hydrologic systems, if the pressure is determined by a more physical closure. We consider such a closure next.

\subsection{Full-cavity closure}

Simply requiring the subglacial layer to be full of water is also a closure (Bartholomaus et al., 2011), which we adopt:

$W=Y$.

The consequences of this closure are explored at some length by Schoof et al. (2012), Hewitt et al. (2012), and Werder et al. (2013), who describe the full-cavity case as the "normal pressure" condition.
Equation (29) obviously allows us to eliminate either $W$ or $Y$ as a state variable. We choose to eliminate $Y$ because $W$ is already part of the conserved mass $W+W_{\text {til. }}$. In the zero till storage case, Eqs. (1), (13), and (29) imply

$\mathcal{O}\left(\left|\boldsymbol{v}_{\mathrm{b}}\right|, W\right)-\mathcal{C}(N, W)+\nabla \cdot \boldsymbol{q}=\frac{m}{\rho_{\mathrm{w}}}$,

which is exactly elliptic pressure Eq. (2.12) of Schoof et al. (2012). They argue that a model based on Eq. (30) should accommodate the possibility of partially empty cavities with $W<Y$ when $P=0$. However, like Werder et al. (2013) who implement the model in two dimensions, we accept a potential loss of model completeness by using a full-cavity model.

\subsection{Englacial porosity as a pressure regularization}

Englacial systems of cracks, crevasses, and moulins have been observed in glaciers (Fountain et al., 2005; Bartholomaus et al., 2008; Harper et al., 2010, for example), and these have been included in combined englacial-subglacial hydrology models (Flowers and Clarke, 2002a; Bartholomaus et al., 2011; Hewitt, 2013; Werder et al., 2013). The englacial system is generally parameterized as having macro-porosity $0 \leq \phi<1$. If the englacial system is efficiently connected to the subglacial water then the amount of englacial water is equivalent to the subglacial pressure, which is reflected by an englacial "water table" in such models.

Bueler (2014) shows that a distributed extension of the lumped englacial-subglacial model in Bartholomaus et al. (2011) gives an equation similar to Eq. (30). The crucial difference from Eq. (30) is that the equation is parabolic for the pressure and not elliptic (compare Hewitt et al., 2012). Based on this analysis, our model uses a parabolic regularization of Eq. (30) which has constant (notional) englacial porosity $\phi_{0}$ :

$$
\begin{aligned}
\frac{\phi_{0}}{\rho_{\mathrm{w}} g} \frac{\partial P}{\partial t}= & -\nabla \cdot \boldsymbol{q}+\frac{m}{\rho_{\mathrm{w}}}+\mathcal{C}(N, W) \\
& -\mathcal{O}\left(\left|\boldsymbol{v}_{\mathrm{b}}\right|, W\right)-\frac{\partial W_{\mathrm{til}}}{\partial t} .
\end{aligned}
$$

Compare Eq. (7) in Hewitt (2013) and Eq. (24) in Werder et al. (2013). Unlike Werder et al. (2013), however, we do not add an englacial water amount variable to the conservation equation, and in this sense the porosity only serves to regularize the pressure equation.

Using englacial porosity as a regularization, as in Eq. (31), allows a user-adjustable trade-off between temporal detail in the pressure evolution vs. computational effort (Van Pelt, 2013). If the englacial porosity $\phi_{0}$ is small then there is a nearly impermeable "cap" on the subglacial system and Eq. (31) is stiff (Ascher and Petzold, 1998). Equation (31) is then similar, in terms of numerical solution, to elliptic Eq. (30). Indeed, if elliptic Eq. (30) is used instead of Eq. (31) then the coupled hydrological equations system is differential algebraic (Ascher and Petzold, 1998), and harder to solve 
numerically. By contrast, local changes in subglacial pressure $P$ propagate to other parts of the connected hydraulic system in a damped way if $\phi_{0}$ is large.

Schoof et al. (2012) show that the mathematical problem encompassing Eq. (30), constraints (4), and appropriate pressure boundary conditions can be written as an elliptic variational inequality (Kinderlehrer and Stampacchia, 1980). Solving this variational inequality problem in two dimensions, at each time step, is asserted to be "prohibitively expensive" by Werder et al. (2013). Our adaptive explicit timestepping scheme (Sect. 6), by contrast, solves Eq. (31), while satisfying constraints (4), at demonstrably reasonable computational cost (Sect. 7).

Stiffness in these pressure equations ultimately follows from the incompressibility of water and the relative nondistensibility (i.e., hardness) of the ice and bedrock. Clarke (2003) addresses this in a physically different manner from englacial porosity. He includes a relaxation (damping) parameter " $\beta$ " which is based on the small compressibility of water, but which is more than 2 orders of magnitude larger than the physical value. Clarke's parameter $\beta$ appears in his equation exactly as $\phi_{0}$ appears in Eq. (31), multiplying the pressure time derivative.

\section{The new subglacial hydrology model in PISM}

\subsection{Summary of the model}

The major evolution equations for the model are mass conservation (Eq. 12), till-stored water layer thickness evolution (Eq. 16), and pressure evolution (Eq. 31). Collected here for clarity they are

$$
\begin{aligned}
& \frac{\partial W}{\partial t}+\frac{\partial W_{\mathrm{til}}}{\partial t}=-\nabla \cdot(\boldsymbol{V} W)+\nabla \cdot(D \nabla W)+\frac{m}{\rho_{\mathrm{w}}}, \\
& \frac{\partial W_{\mathrm{til}}}{\partial t}=\frac{m}{\rho_{\mathrm{w}}}-C_{\mathrm{d}}, \\
& \frac{\phi_{0}}{\rho_{\mathrm{w}} g} \frac{\partial P}{\partial t}+\frac{\partial W_{\mathrm{til}}}{\partial t}=-\nabla \cdot(\boldsymbol{V} W)+\nabla \cdot(D \nabla W)+\frac{m}{\rho_{\mathrm{w}}} \\
& \quad+c_{2} A\left(P_{\mathrm{o}}-P\right)^{3} W-c_{1}\left|\boldsymbol{v}_{\mathrm{b}}\right|\left(W_{\mathrm{r}}-W\right)_{+} \cdot
\end{aligned}
$$

Also recall these definitions:

$$
\begin{aligned}
D & =\rho_{\mathrm{w}} g K W & & \text { diffusivity, } \\
K & =k W^{\alpha-1}\left|\nabla\left(P+\rho_{\mathrm{w}} g b\right)\right|^{\beta-2} & & \text { effective conductivity, } \\
P_{\mathrm{o}} & =\rho_{i} g H & & \text { overburden pressure, and } \\
\boldsymbol{V} & =-K \nabla\left(P+\rho_{\mathrm{w}} g b\right) & & \text { velocity. }
\end{aligned}
$$

Equations (32) are coupled to ice dynamics by MohrCoulomb Eq. (18) and till effective pressure Eqs.( 23) and (24).

The model includes these bounds on major variables:

$0 \leq W, \quad 0 \leq W_{\text {til }} \leq W_{\text {til }}^{\max }, \quad 0 \leq P \leq P_{\mathrm{o}}$.
As a result of these inequalities, free boundaries arise in the domain. In particular, free boundaries occur at locations where $m$ is sufficiently negative to drive $W$ to 0 or where the pressure $P$ goes to 0 or overburden.

A coupled weak formulation of Eq. (32) and constraints (33) would be a mathematically rigorous unified description of the free boundary conditions, but this paper takes a more pragmatic approach, as follows. First, PISM uses a periodic domain for whole ice sheet computations (Sect. 7), so the computational domain has no classical boundary. Second, inequalities (33) are enforced in our coupled explicit scheme by truncation-projection (Sect. 6). Third, at ice-free land and ocean (i.e., ice shelf or ice-free ocean) grid locations, pressure $P$ is determined by atmospheric or ocean pressure, respectively. Fourth and finally, at ice-free land and ocean grid locations the mass-conservation equation effectively has $m$ sufficiently negative so that water which flows or diffuses into that grid location during a time step is fully removed and thus $W=0$ and $W_{\text {til }}=0$; see the "mask" variables in Sect. 6.

In this model the pressure $P$ does not feed back to ice dynamics through changing the basal shear stress applied to the ice. Thus, modeled cavity size, i.e., the thickness $W$ of the water in the linked-cavity system, also does not affect ice dynamics. Instead, as clearly stated in Sect. 4, the yield stress $\tau_{\mathrm{c}}$ is determined by the amount $W_{\mathrm{til}}$ of water in the till. Under general conditions of significant basal melting, or surface input, so that $m>\rho_{\mathrm{W}} C_{\mathrm{d}}$, the second equation in system Eq. (32) causes $W_{\text {til }}$ to increase up to its limit $W_{\text {til }}^{\max }$. Ongoing significant melt then causes water to pass into the linkedcavity system, at which point $W$ generally increases according to the first equation in the system, and $P$ evolves according to the third. Under these conditions the term $\partial W_{\text {til }} / \partial t$ is 0 in the first and third equations because $W_{\text {til }}$ is unchangingly at its maximum value. In summary, water input is first put into the till and then "cascades" into the linked-cavity system.

As in Table 2, the functions in the model can be categorized into state functions, which must be provided with initial values, input functions, which are either supplied by observations or by other components of an ice sheet model, and output functions which are supplied to other components of the ice sheet model. In two-way coupling the ice dynamics model passes $H, m$, and $\left|\boldsymbol{v}_{\mathrm{b}}\right|$ to the subglacial hydrology model, and $\tau_{\mathrm{c}}$ is returned.

\subsection{Reduction to existing models}

Four reductions (limiting cases) of model Eq. (32) can now be stated precisely:

i. The zero till storage $\left(W_{\text {til }}^{\max }=0\right)$ and zero englacial porosity $\left(\phi_{0}=0\right)$ case of Eq. (32) is essentially the model described by Schoof et al. (2012). Recalling that 
$\boldsymbol{q}=-K W \nabla \psi$, the equations are

$$
\begin{aligned}
& \frac{\partial W}{\partial t}=-\nabla \cdot(K W \nabla \psi)+\frac{m}{\rho_{\mathrm{w}}}, \\
& 0=\nabla \cdot(K W \nabla \psi)+\frac{m}{\rho_{\mathrm{w}}} \\
& \quad+c_{2} A\left(P_{\mathrm{o}}-P\right)^{3} W-c_{1}\left|\boldsymbol{v}_{\mathrm{b}}\right|\left(W_{\mathrm{r}}-W\right)_{+} .
\end{aligned}
$$

The bounds $W \geq 0$ and $0 \leq P \leq P_{\mathrm{O}}$ are unchanged. Model (32) is a parabolic version of model (34), regularized using a notional connection to porous englacial storage, and with coupling to till storage.

ii. The $P=P_{\mathrm{o}}$ limit of Eqs. (32), in which the evolution equation for pressure is ignored, is essentially the model for "routing" water to subglacial lakes under cold ice sheets used by Siegert et al. (2007) and Livingstone et al. (2013). As noted in Sect. 4, the $W_{\text {til }}^{\max }=0$ and $\alpha=1$ case of this model routes water with a velocity which is determined entirely by ice and bedrock geometry.

iii. The non-distributed "lumped" form of Eqs. (32), in which, in particular, $\nabla \cdot \boldsymbol{q}=\frac{\left(q_{\text {out }}-q_{\text {in }}\right)}{L}$ where $L$ is the length of the glacier and $q_{\text {out }}, q_{\text {in }}$ are given by observations, is the model of Bartholomaus et al. (2011); see Bueler (2014).

iv. The undrained plastic bed (UPB) model of Tulaczyk et al. (2000b) arises as the $W=0, \boldsymbol{q}=0, \phi_{0}=0$ reduction of Eqs. (32). This model depends on frictionheating feedback to keep $W_{\text {til }}$ bounded, which is not effective if local friction heating is a non-local function of changes in till strength. Bueler and Brown (2009) therefore enforce $W_{\mathrm{til}} \leq W_{\mathrm{til}}^{\max }$ by removing water above the capacity $W_{\text {til }}^{\max }$, giving a minimal non-conservative, but "drained," version of the UPB model.

The above list does not imply that all possible subglacial hydrology models are reductions of ours. For example, the subglacial hydrology model of Johnson and Fastook (2002) is a variation on idea (ii) above but it is not a reduction. The Flowers and Clarke (2002a) model mentioned in Sect. 4.1 is also not a reduction, though a significant connection is explained in the Appendix.

Two-dimensional models which include conduits (Schoof, $2010 \mathrm{~b}$ ) are not reductions of our model. Conduit evolution is numerically straightforward to implement in onedimensional hydrology models (Hewitt et al., 2012; Van der Wel et al., 2013), but when extended to two-horizontal dimensions all existing models (Schoof, 2010b; Hewitt, 2013; Werder et al., 2013) become "lattice" models without a known continuum limit. Our model has no conduit-like evolution equations at all, though the gradient-descent locations of characteristic curves from models using idea (ii) may correspond to the locations of conduits in some cases.

\subsection{Steady states}

The steady form of model Eqs. (32), stated using $\alpha=1, \beta=$ 2 , and $W_{\text {til }}^{\max }=0$ for simplicity, can be written as follows in terms of $\boldsymbol{V}, \boldsymbol{q}, W, P$ :

$$
\begin{aligned}
& \boldsymbol{V}=-k \nabla\left(P+\rho_{\mathrm{w}} g b\right), \\
& \boldsymbol{q}=\boldsymbol{V} W-\rho_{\mathrm{w}} g k W \nabla W, \\
& 0=-\nabla \cdot \boldsymbol{q}+\frac{m}{\rho_{\mathrm{w}}}, \\
& 0=c_{2} A\left(P_{\mathrm{o}}-P\right)^{3} W-c_{1}\left|\boldsymbol{v}_{\mathrm{b}}\right|\left(W_{\mathrm{r}}-W\right)_{+} .
\end{aligned}
$$

These steady-state equations are also stated in the onedimensional case by Schoof et al. (2012). Observe that the equations describing mass conservation (Eq. 37) and cavity opening/closing processes (Eq. 38) have become decoupled.

We make three observations about solutions to Eqs. (35)(38)

i. From Eq. (38) there is a functional relationship $P=$ $P(W)$.

ii. By Eqs. (35) and (38), the apparently advective flux " $V W$ " in Eq. (36) actually acts diffusively.

iii. Radial nearly exact solutions can be constructed.

In Appendix A we detail points (i) and (ii). Observation (iii) is addressed next.

\subsection{A nearly exact steady-state solution}

For the purpose of verifying numerical schemes we have built a two-dimensional, nearly exact solution for $W$ and $P$, in a case with nontrivial overburden pressure and ice sliding. It depends on the numerical solution of a scalar first-order ordinary differential equation (ODE) initial value problem, something we can do with high accuracy. Note that Schoof et al. (2012) also construct traveling-wave (i.e., non-steady) exact solutions in one dimension.

We solve the flat bed $(b=0)$ angularly symmetric case of coupled Eqs. (35)-(38). By assuming spatially constant water input $\left(m=m_{0}\right)$, a parabolic ice thickness profile in the radial coordinate $r$, and a particular profile of sliding, the equations reduce to a single first-order ODE in $r$ for the water thickness $W(r)$. The sliding is given by a function $\left|\boldsymbol{v}_{\mathrm{b}}(r)\right|$ with onset of sliding at location $r=5 \mathrm{~km}$, about onefourth of the ice cap radius $r=22.5 \mathrm{~km}$. The pressure $P(r)$ is then determined from $W(r)$ by the functional relationship Eq. (A3) which applies in steady state (Appendix A).

To compute the nearly exact solution, we use adaptive numerical ODE solvers, both a Runge-Kutta method and a variable-order stiff solver, with relative tolerance $10^{-12}$ and absolute tolerance $10^{-9}$. The two solvers gave identical results to more than six digits. The result $W(r)$ is shown in Fig. 2, which also shows the regions of the $r, W$ plane which correspond to overpressure $\left(P=P_{\mathrm{o}}\right.$ in our model $)$, normal 


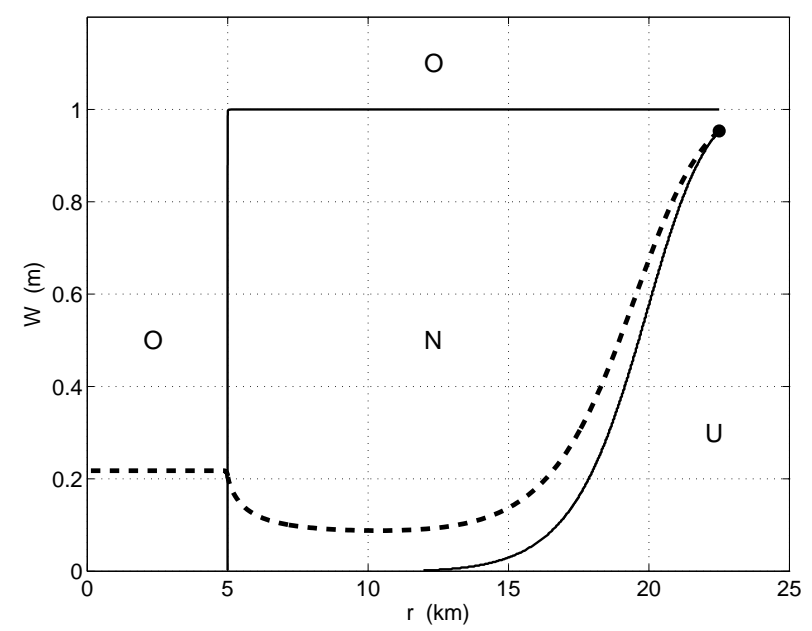

Figure 2. A nearly exact radial, steady solution for water thickness $W(r)$ (dashed). In $r$-vs.- $W$ space the overpressure $(O)$, normal pressure $(N)$, and under-pressure $(U)$ regions (solid curves) are determined by ice geometry and sliding velocity, because this is steady state.

pressure $\left(0<P<P_{\mathrm{o}}\right)$, and under pressure $(P=0)$. Figure 3 shows the corresponding pressure solution $P(r)$. Starting at the margin, we see that the solution is in the normal pressure region as $r$ decreases, until the onset of sliding $(r=5 \mathrm{~km})$ where it switches into the overpressure case (because there is no sliding upstream).

Verification results using the nearly exact solution appear in Sect. 7. Our numerical methods (next section) use a cartesian $(x, y)$ grid unrelated to the radial nearly exact solution, so numerical error comes from generic relationships between exact solution features and the grid.

\section{Numerical schemes}

Equations (32) are discretized by explicit finite difference methods (Morton and Mayers, 2005). A centered, secondorder scheme is applied to the diffusion part of the massconservation equation in model (32), but two upwind-type schemes for the advection part are compared, namely, firstorder "donor cell" upwind method (LeVeque, 2002) and a higher-order flux-limited upwind-biased method (Hundsdorfer and Verwer, 2003). All the numerical schemes are implemented in parallel using the Portable, Extensible Toolkit for Scientific computation (PETSc) library (Balay et al., 2011).

\subsection{Discretization of the mass-conservation equation}

To set notation, suppose the rectangular computational domain has $M_{x} \times M_{y}$ grid points $\left(x_{i}, y_{j}\right)$ with uniform spacing $\Delta x, \Delta y$. Let $W_{i, j}^{l} \approx W\left(t_{l}, x_{i}, y_{j}\right),\left(W_{\mathrm{til}}\right)_{i, j}^{l} \approx W_{\mathrm{til}}\left(t_{l}, x_{i}, y_{j}\right)$, and $P_{i, j}^{l} \approx P\left(t_{l}, x_{i}, y_{j}\right)$ denote the numerical approximations.

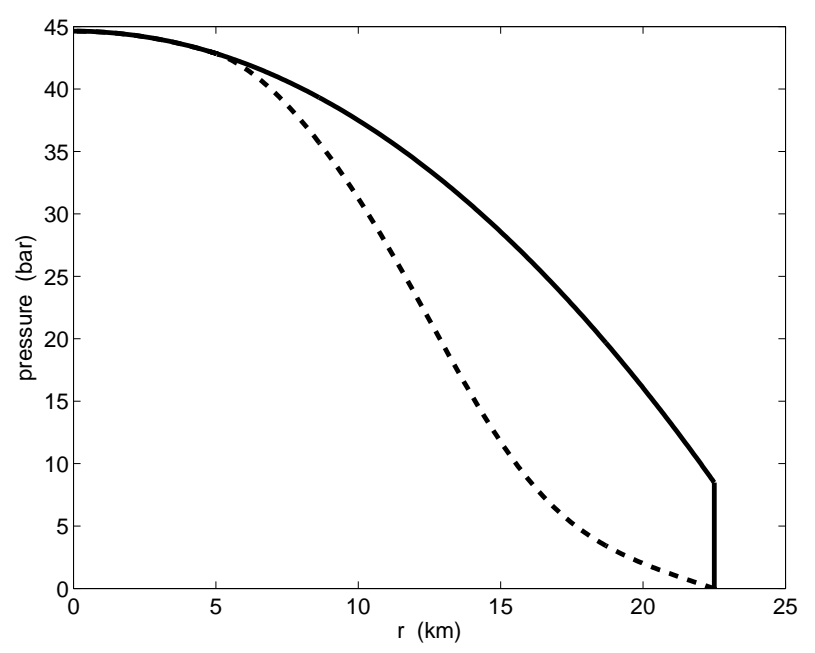

Figure 3. A nearly exact radial, steady solution for pressure $P(r)$ (dashed) and overburden pressure $P_{\mathrm{O}}$ (solid).

We compute velocity components and flux components at the staggered (cell-face-centered) points, shown in Fig. 4, from centered finite difference approximations of Eqs. (10) and (11). We use "compass" indices for such staggered values, so that, for example, the "east" and "north" staggered water layer thicknesses are computed by averaging regular grid values:

$W_{\mathrm{e}}=\frac{\left(W_{i, j}^{l}+W_{i+1, j}^{l}\right)}{2}, \quad W_{\mathrm{n}}=\frac{\left(W_{i, j}^{l}+W_{i, j+1}^{l}\right)}{2}$.

The nonlinear effective conductivity $K$ from Eq. (9) is also needed at staggered locations. As a notational convenience define $R=P+\rho_{\mathrm{w}} g b$ and define these staggered-grid values (compare Mahaffy, 1976):

$$
\begin{aligned}
\Pi_{\mathrm{e}}= & \left|\frac{R_{i+1, j}-R_{i, j}}{\Delta x}\right|^{2} \\
& +\left|\frac{R_{i+1, j+1}+R_{i, j+1}-R_{i+1, j-1}-R_{i, j-1}}{4 \Delta y}\right|^{2}, \\
\Pi_{\mathrm{n}}= & \left|\frac{R_{i+1, j+1}+R_{i+1, j}-R_{i-1, j+1}-R_{i-1, j}}{4 \Delta x}\right|^{2} \\
& +\left|\frac{R_{i, j+1}-R_{i, j}}{\Delta y}\right|^{2} .
\end{aligned}
$$

Thereby define

$$
K_{\mathrm{e}}=k W_{\mathrm{e}}^{\alpha-1} \Pi_{\mathrm{e}}^{\frac{(\beta-2)}{2}}, \quad K_{\mathrm{n}}=k W_{\mathrm{n}}^{\alpha-1} \Pi_{\mathrm{n}}^{\frac{(\beta-2)}{2}} .
$$

The velocity components $(u, v)$ of the water velocity $\boldsymbol{V}$ are then found by differencing:

$$
u_{\mathrm{e}}=-K_{\mathrm{e}} \frac{R_{i+1, j}-R_{i, j}}{\Delta x}, \quad v_{\mathrm{n}}=-K_{\mathrm{n}} \frac{R_{i, j+1}-R_{i, j}}{\Delta y} .
$$




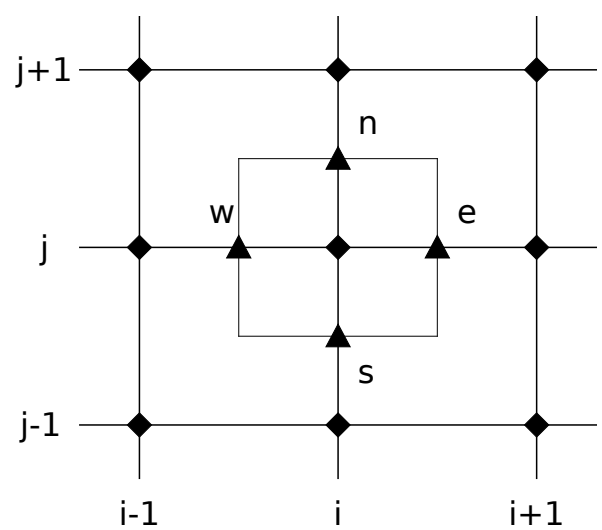

Figure 4. Numerical schemes Eqs. (44) and (49) use a grid-pointcentered cell. Velocities, diffusivities, and fluxes are evaluated at staggered-grid locations (triangles at centers of cell edges) denoted by compass notation $e, w, n, s$. State functions $W, W_{t i l}, P$ are located at regular grid points (diamonds).

For diffusivity we simply have

$D_{\mathrm{e}}=\rho_{\mathrm{w}} g K_{\mathrm{e}} W_{\mathrm{e}}, \quad D_{\mathrm{n}}=\rho_{\mathrm{w}} g K_{\mathrm{n}} W_{\mathrm{n}}$.

We get the remaining staggered-grid quantities by shifting indices.

Define $Q_{\mathrm{e}}\left(u_{\mathrm{e}}\right), Q_{w}\left(u_{w}\right), Q_{\mathrm{n}}\left(v_{\mathrm{n}}\right)$, and $Q_{s}\left(v_{s}\right)$ as the facecentered (staggered-grid) normal components of the advective flux $V W$; more detail is given in the next subsection. The grid values of $\mathcal{D}=\nabla \cdot \boldsymbol{q}=\nabla \cdot(\boldsymbol{V} W)-\nabla \cdot(D \nabla W)$ using Eqs. (41) and (42) now become

$$
\begin{aligned}
\mathcal{D}_{i, j} & =\frac{Q_{\mathrm{e}}\left(u_{\mathrm{e}}\right)-Q_{w}\left(u_{w}\right)}{\Delta x}+\frac{Q_{\mathrm{n}}\left(v_{\mathrm{n}}\right)-Q_{s}\left(v_{s}\right)}{\Delta y} \\
& -\frac{D_{\mathrm{e}}\left(W_{i+1, j}^{l}-W_{i, j}^{l}\right)-D_{w}\left(W_{i, j}^{l}-W_{i-1, j}^{l}\right)}{\Delta x^{2}} \\
& -\frac{D_{\mathrm{n}}\left(W_{i, j+1}^{l}-W_{i, j}^{l}\right)-D_{s}\left(W_{i, j}^{l}-W_{i, j-1}^{l}\right)}{\Delta y^{2}} .
\end{aligned}
$$

Local conservation is ensured by using $Q_{\mathrm{e}}\left(u_{\mathrm{e}}\right)$ in computing $\mathcal{D}_{i, j}$ equal to $Q_{w}\left(u_{w}\right)$ used in $\mathcal{D}_{i+1, j}$, and so on.

Our scheme for approximating mass conservation Eq. (12) is

$$
\frac{W_{i, j}^{l+1}-W_{i, j}^{l}}{\Delta t}+\frac{\left(W_{\mathrm{til}}\right)_{i, j}^{l+1}-\left(W_{\mathrm{til}}\right)_{i, j}^{l}}{\Delta t}=-\mathcal{D}_{i, j}+\frac{m_{i j}}{\rho_{\mathrm{w}}} .
$$

The updated value of $W_{\text {til }}$, which appears on the left side of Eq. (44), is computed by trivial integration of Eq. (16),

$\left(W_{\mathrm{til}}\right)_{i, j}^{l+1}=\left(W_{\mathrm{til}}\right)_{i, j}^{l}+\Delta t\left(\frac{m_{i j}}{\rho_{\mathrm{w}}}-C_{\mathrm{d}}\right)$.

The given value $W_{\text {til }}^{l+1}$ is used if it is in the closed interval $\left[0, W_{\mathrm{til}}^{\max }\right]$, but otherwise the bounds $0 \leq W_{\mathrm{til}} \leq W_{\mathrm{til}}^{\max }$ are enforced. Once $W_{\text {til }}^{l+1}$ is computed, the value of $W^{l+1}$ can be updated by Eq. (44) in a mass-conserving way.
Assuming no error in the flux components $Q$, the local truncation error (Morton and Mayers, 2005) of scheme Eq. (44) would be $O\left(\Delta t^{1}+\Delta x^{2}+\Delta y^{2}\right)$ as an approximation of Eq. (12). The actual truncation error depends on the approximation of the discrete fluxes, addressed next.

\subsection{Discrete advective fluxes}

We test two flux-discretization schemes, namely, a firstorder upwind scheme and the Koren flux-limited third-order scheme (Hundsdorfer and Verwer, 2003). Both schemes achieve non-oscillation and positivity, but with different local truncation error and complexity of implementation. The third-order scheme is best explained as a modification of our conservative ("donor cell"; LeVeque, 2002) first-order upwind scheme.

For a flux-limited scheme, the following formulas apply in the cases $u_{\mathrm{e}} \geq 0, u_{\mathrm{e}}<0, v_{\mathrm{n}} \geq 0$, and $v_{\mathrm{n}}<0$ :

$$
\begin{aligned}
& Q_{\mathrm{e}}\left(u_{\mathrm{e}}\right)=u_{\mathrm{e}}\left[W_{i, j}+\Psi\left(\theta_{i}\right)\left(W_{i+1, j}-W_{i, j}\right)\right], \\
& Q_{\mathrm{e}}\left(u_{\mathrm{e}}\right)=u_{\mathrm{e}}\left[W_{i+1, j}+\Psi\left(\left(\theta_{i+1}\right)^{-1}\right)\left(W_{i, j}-W_{i+1, j}\right)\right], \\
& Q_{\mathrm{n}}\left(v_{\mathrm{n}}\right)=v_{\mathrm{n}}\left[W_{i, j}+\Psi\left(\theta_{j}\right)\left(W_{i, j+1}-W_{i, j}\right)\right], \\
& Q_{\mathrm{n}}\left(v_{\mathrm{n}}\right)=v_{\mathrm{n}}\left[W_{i, j+1}+\Psi\left(\left(\theta_{j+1}\right)^{-1}\right)\left(W_{i, j}-W_{i, j+1}\right)\right],
\end{aligned}
$$

where the subscripted $\theta$ quotients are

$\theta_{i}=\frac{W_{i, j}-W_{i-1, j}}{W_{i+1, j}-W_{i, j}}, \quad \theta_{j}=\frac{W_{i, j}-W_{i, j-1}}{W_{i, j+1}-W_{i, j}}$.

The first-order upwind scheme simply sets $\Psi(\theta)=0$ in formulas Eq. (46). The Koren scheme limits its third-order and positive-coefficient correction to the upwind scheme by using this formula (Hundsdorfer and Verwer, 2003)

$\Psi(\theta)=\max \left\{0, \min \left\{1, \theta, \frac{1}{3}+\frac{1}{6} \theta\right\}\right\}$.

When using the Koren flux limiter, the stencil in Fig. 4 is extended because regular grid neighbors $W_{i+2, j}, W_{i-2, j}$, $W_{i, j+2}, W_{i, j-2}$ are also involved in updating $W_{i, j}$. The flux-correction-limited Koren third-order scheme bypasses the first-order limitation of positive linear finite differencevolume schemes imposed by Godunov's barrier theorem (Hundsdorfer and Verwer, 2003, Sect. I.7.1) by using a nonlinear correction formula. Though the Koren scheme is thirdorder where smoothness allows, it reverts to first-order at extrema and jumps where $\theta \gg 1$ or $\theta \ll 1$.

For either scheme, if the water input $m$ is negative then we must actively enforce, by truncation, the positivity of the water thickness $W$. In fact, positivity of the source-free advection-diffusion scheme, a desirable property which we can show by standard methods (Hundsdorfer and Verwer, 2003), does not ensure positivity of the solution if there is water removal, i.e., if $\frac{m}{\rho_{\mathrm{w}}}-\frac{\partial W_{\text {til }}}{\partial t}<0$. 


\subsection{Discretization of the pressure equation}

Pressure evolution Eq. (31) is a nonlinear diffusion with "reaction" terms from the opening and closing of cavities. However, our numerical scheme for this equation is similar to the scheme for the mass-conservation equation (Sect. 6.1) because the spatial derivatives are actually the same in each equation, namely, $\nabla \cdot \boldsymbol{q}$. Thus, we reuse the computation of those derivatives, namely, scheme Eq. (43), which gives $\mathcal{D}_{i, j}$.

Let $\mathcal{O}_{i j}, \mathcal{C}_{i j}$ be the gridded values of the zeroth-order (i.e., without spatial derivatives) opening and closing rates; see Eqs. (14), (15). Define the sum of all zeroth-order terms:

$Z_{i j}=\mathcal{C}_{i j}-\mathcal{O}_{i j}+\frac{m_{i j}}{\rho_{\mathrm{w}}}-\frac{\left(W_{\mathrm{til}}\right)_{i j}^{l+1}-\left(W_{\mathrm{til}}\right)_{i j}^{l}}{\Delta t}$

Using Eq. (43) for the flux divergence, the scheme for pressure Eq. (31) is

$$
\frac{\phi_{0}}{\rho_{\mathrm{w}} g} \frac{P_{i, j}^{l+1}-P_{i, j}^{l}}{\Delta t}=-\mathcal{D}_{i, j}+Z_{i j}
$$

Because Eq. (48) uses the updated value $\left(W_{\text {til }}\right)_{i j}^{l+1}$, Eq. (45) must be applied before Eq. (49) can be used to update $P$. There are also special cases at the boundaries of the region where $W>0$; see Sect. 6.5.

\subsection{Stability of time stepping}

A sufficient condition for stability of mass-conservation scheme Eq. (44) comes from combining sufficient conditions for stability of the advection and diffusion parts. For the advection part we first define $\Delta t_{\mathrm{CFL}}$, after the well-known Courant-Friedrichs-Lewy restriction for advection schemes (Morton and Mayers, 2005), by

$\Delta t_{\mathrm{CFL}}\left(\frac{\max |u|}{\Delta x}+\frac{\max |v|}{\Delta y}\right)=\frac{1}{2}$,

where $\boldsymbol{V}=(u, v)$ is the velocity of the water in the distributed system. For the diffusion part we define $\Delta t_{\mathrm{W}}$ by

$\Delta t_{\mathrm{W}} \max D\left(\frac{1}{\Delta x^{2}}+\frac{1}{\Delta y^{2}}\right)=\frac{1}{4}$.

The condition $\Delta t \leq \min \left\{\Delta t_{\mathrm{CFL}}, \Delta t_{\mathrm{W}}\right\}$ is sufficient for stability and convergence of scheme Eq. (44) if $\boldsymbol{V}, D$, and $m$ were all externally provided functions, i.e., in the case where Eqs. (32) are decoupled. We can show this by maximum principle arguments for the first-order upwind advection choice (Morton and Mayers, 2005), but standard theory at least suggests the same conclusion for the higher-order flux-limited advection scheme (Hundsdorfer and Verwer, 2003).

These time-step restrictions can be understood by considering an example. We ran the model on a $\Delta x=\Delta y=250 \mathrm{~m}$ grid to approximate steady state for the subglacial hydrology of Nordenskiöldbreen (Van Pelt, 2013). We used realistic inputs for $H, b$, and $m$, but a spatially constant ice sliding rate of $\left|v_{\mathrm{b}}\right|=50 \mathrm{~m} \mathrm{a}^{-1}$; other parameter values were from Table 1 . The result is that the maximum computed water speed $|\boldsymbol{V}|$ is about $0.2 \mathrm{~m} \mathrm{~s}^{-1}$ so Eq. (50) gives $\Delta t_{\mathrm{CFL}} \approx 300 \mathrm{~s}$. Computed diffusivity $D=\rho_{\mathrm{w}} g K W$ has a maximum value that varies significantly in time, $0.1 \leq \max D \leq 5 \mathrm{~m}^{2} \mathrm{~s}^{-1}$. Using a typical value $\max D=1 \mathrm{~m}^{2} \mathrm{~s}^{-1}$ in Eq. (51) gives $\Delta t_{\mathrm{W}} \approx$ $8000 \mathrm{~s}$. Thus, in this simulation $\Delta t_{\mathrm{W}} \approx 25 \Delta t_{\mathrm{CFL}}$. This example suggests that, unless both the maximum speed $|\boldsymbol{V}|$ is unusually low, and deep subglacial lakes develop so that $\max D$ is large, the diffusive timescale is significantly longer than the CFL timescale. While the scaling $\Delta t_{\mathrm{W}}=O\left(\Delta x^{2}\right)$ vs. $\Delta t_{\mathrm{CFL}}=O\left(\Delta x^{1}\right)$ makes it clear that under sufficient spatial grid refinement $\Delta t_{\mathrm{W}}$ is controlling, we suspect that $\Delta t_{\mathrm{CFL}}$ is controlling for $\Delta x>100 \mathrm{~m}$.

However, the time-step restriction from the pressureequation scheme is typically shorter than either $\Delta t_{\mathrm{W}}$ or $\Delta t_{\mathrm{CFL}}$. The time-step restriction for scheme Eq. (49) is comparable to $\Delta t_{\mathrm{W}}$, and we define $\Delta t_{\mathrm{P}}$ by

$\Delta t_{\mathrm{P}}\left(\frac{2 \max D}{\phi_{0}}\right)\left(\frac{1}{\Delta x^{2}}+\frac{1}{\Delta y^{2}}\right)=1$.

If the time step is set by

$\Delta t=\min \left\{\Delta t_{\mathrm{CFL}}, \Delta t_{\mathrm{W}}, \Delta t_{\mathrm{P}}\right\}$,

then we observe in practice that the coupled scheme consisting of Eqs. (44), (45), and (49) is stable.

Recalling Eq. (51), however, $\Delta t_{\mathrm{P}}$ is actually a fraction of $\Delta t_{\mathrm{W}}$, namely, $\Delta t_{\mathrm{P}}=2 \phi_{0} \Delta t_{\mathrm{W}}$. If we return to the above example for Nordenskiöldbreen, with $\phi_{0}=0.01$ we have $\Delta t_{\mathrm{W}} \approx 8000 \mathrm{~s}, \Delta t_{\mathrm{CFL}} \approx 300 \mathrm{~s}$, and $\Delta t_{\mathrm{P}} \approx 160 \mathrm{~s}$. In this case the pressure scheme has the shortest time step, but it is comparable to CFL. Because $\Delta t_{\mathrm{P}}$ is $O\left(\Delta x^{2}\right)$, the pressure scheme restriction is certainly controlling for sufficiently fine grids. However, the time step $\Delta t_{\mathrm{P}}$ also scales with porosity $\phi_{0}$, so we can make it more or less severe by adjusting that parameter.

If implicit time stepping were instead used for the pressure equation, which would require overt variational inequality treatment to preserve physical pressure bounds (Schoof et al., 2012), then the timescales $\Delta t_{\mathrm{W}}, \Delta t_{\mathrm{CFL}}$ addressed here would be the only restrictions. The time-step restriction $\Delta t_{\mathrm{W}}$ could also be removed by implicit steps for the mass-conservation equation, though again this requires a variational inequality formulation because of the lower bound $W \geq 0$. Our observation above that $\Delta t_{\mathrm{CFL}} \ll \Delta t_{\mathrm{W}}$ for practical ice sheet grids suggests that implicit time stepping only for the diffusion part of the mass-conservation equation is not beneficial.

\subsection{One time step of the model}

Mathematical model Eqs. (32) evolves the fields $W, W_{\mathrm{til}}$, and $P$. Here we describe one time step of the fully discretized coupled evolution. 
For convenience only we denote the ice geometry, bed geometry, and sliding speed (i.e., $H_{i, j}, b_{i, j},\left(P_{\mathrm{o}}\right)_{i, j}$, and $\left.\left|\boldsymbol{v}_{\mathrm{b}}\right|_{i, j}\right)$ as though they are all time independent. The geometry may be quite general, with ice-free land, floating ice shelf, or icefree ocean allowed at any location $\left(x_{i}, y_{j}\right)$. The geometry input data determine boolean "masks" on the grid, based on 0 as the sea level elevation:

$$
\begin{aligned}
\text { icefree }_{i, j} & =\left(H_{i, j}=0\right) \&\left(b_{i, j}>0\right), \\
\text { float }_{i, j} & =\left(\rho_{i} H_{i, j}<-\rho_{\mathrm{sw}} b_{i, j}\right),
\end{aligned}
$$

where $\rho_{\mathrm{sw}}=1028.0$ is sea-water density. Note float $_{i, j}$ is true both where there is floating ice shelf and where the ocean is ice free. The subglacial hydrology model exists only for grounded ice, that is, only if both flags icefree and float are false.

One time step follows this algorithm:

i. Start with values $W_{i, j}^{l},\left(W_{\mathrm{til}}\right)_{i, j}^{l}, P_{i, j}^{l}$ which satisfy bounds $W \geq 0,0 \leq W_{\text {til }} \leq W_{\text {til }}^{\max }$, and $0 \leq P \leq P_{\mathrm{o}}$.

ii. Get $\left(W_{\mathrm{til}}\right)_{i, j}^{l+1}$ with Eq. (45). Enforce $0 \leq W_{\mathrm{til}} \leq W_{\mathrm{til}}^{\max }$. If icefree $_{i, j}$ or float $i, j$ then set $\left(W_{\mathrm{til}}\right)_{i, j}^{l+1}=0$.

iii. Get $W$ values averaged onto the staggered grid from Eq. (39), staggered-grid values of the effective conductivity $K$ from Eq. (40), velocity components $u, v$ at staggered-grid locations from Eq. (41), and staggeredgrid values of the diffusivity $D$ from Eq. (42).

iv. Get time step $\Delta t$ from Eq. (53).

v. Using Eq. (46) and a flux limiter $\psi(\theta)$, compute the advective fluxes $Q_{\mathrm{e}}\left(\alpha_{\mathrm{e}}\right)$ and $Q_{\mathrm{n}}\left(\beta_{\mathrm{n}}\right)$ at all staggered-grid points.

vi. Get flux divergence approximations $\mathcal{D}_{i, j}$ from Eq. (43).

vii. If icefree $_{i, j}$ then set $P_{i, j}^{l+1}=0$. If float fl,j $_{j}$ then set $P_{i, j}^{l+1}=\left(P_{\mathrm{o}}\right)_{i, j}$. If $W_{i, j}^{l}=0$, and if icefree $i_{i, j}$ and float $_{i, j}$ are both false, then either set $P_{i, j}^{l+1}=\left(P_{\mathrm{o}}\right)_{i, j}$ (no sliding) or $P_{i, j}^{l+1}=0$ (any sliding). Otherwise use Eq. (49) to compute $P_{i, j}^{l+1}$.

viii. If $P_{i, j}^{l+1}$ does not satisfy bounds $0 \leq P \leq P_{\mathrm{o}}$ then truncate/project into this range.

ix. If icefree $_{i, j}$ or float ${ }_{i, j}$ then set $W_{i, j}^{l+1}=0$. Otherwise use Eq. (44) to compute values for $W_{i, j}^{l+1}$.

x. If $W_{i, j}^{l+1}<0$ then truncate/project to get $W_{i, j}^{l+1}=0$.

xi. Update time $t_{l+1}=t_{l}+\Delta t$ and repeat at (i)
This algorithm goes with a reporting scheme for mass conservation. Note that in steps (ii) and (ix) water is lost or gained at the margin where either the ice thickness goes to 0 on land (margins), or at locations where the ice becomes floating ice (grounding lines). Because such loss/gain may be the modeling goal - users want hydrological discharge - these amounts are reported. This reporting scheme also tracks the projections in step (x), which represent a massconservation error which goes to 0 in the continuum limit $\Delta t \rightarrow 0$.

\subsection{Run-time options for hydrology models}

Option -hydrology NAME, where NAME is one of the three headings below, chooses the model equations.

distributed: this model is governed by the full set of Eqs. (32) in Sect. 5. The full set of parameters (Table 1) and variables (Table 2 ) are active in this model.

routing: in this reduced model the equation for pressure evolution is replaced by $P=P_{\mathrm{o}}$. The evolution equations for the state variables $W$ and $W_{t i l}$, and the bounds $0 \leq W$ and $0 \leq W_{\text {til }} \leq W_{\text {til }}^{\max }$, are unchanged.

null: this further-reduced model is non-conserving. It has only the state variable $W_{\text {til }}$ which is subject to bounds $0 \leq$ $W_{\text {til }} \leq W_{\text {til }}^{\max }$ and evolves by Eq. (16).

The correspondence between the notation in this paper and PISM's configurable parameters is shown in Table 3. These parameters can be set at runtime by using the parameter name as an option, or by setting a pism_overrides variable in a NetCDF file which is read with the -config_override option (PISM authors, 2015). File src/pism_config.cdl determines the default values and units.

\section{Results}

\subsection{Verification of the coupled model}

By using the coupled, steady-state, nearly exact solution (Sect. 5.4) we verified most of the numerical schemes described above. (Verification is the process of measuring and analyzing the errors made by the numerical scheme, especially as the numerical grid is refined (Wesseling, 2001).) To do this we initialized our time-stepping numerical scheme with the nearly exact steady solution and we measured the error relative to the exact values after 1 model month. The continuum time-dependent model Eq. (32) would cause no drift away from steady state, so any drift is numerical error. We did runs on grids decreasing by factors of 2 from $2 \mathrm{~km}$ to $125 \mathrm{~m}$. Figure 5 shows the results based on the first-order upwind method for the fluxes.

This convergence evidence suggests that we have implemented the numerical schemes in Sect. 6, for the coupled advection-diffusion-reaction equations for $W$ and $P$, correctly. The rate of convergence in this verification case is 
Table 3. Correspondence between PISM parameter names and symbols in this paper (Table 1). All are used in the distributed model, with indicated subsets used in the routing and null models.

\begin{tabular}{|c|c|c|c|}
\hline PISM parameter name & Symbol & routing & null \\
\hline fresh_water_density & $\rho_{\mathrm{W}}$ & $\times$ & $\times$ \\
\hline hydrology_cavitation_opening_coefficient & $c_{1}$ & & \\
\hline hydrology_creep_closure_coefficient & $c_{2}$ & & \\
\hline hydrology_gradient_power_in_flux & $\beta$ & $\times$ & \\
\hline hydrology_hydraulic_conductivity & $k$ & $\times$ & \\
\hline hydrology_regularizing_porosity & $\phi_{0}$ & & \\
\hline hydrology_roughness_scale & $W_{\mathrm{r}}$ & & \\
\hline hydrology_thickness_power_in_flux & $\alpha$ & $\times$ & \\
\hline hydrology_tillwat_decay_rate & $C_{\mathrm{d}}$ & $\times$ & $\times$ \\
\hline hydrology_tillwat_max & $W_{\text {til }}^{\max }$ & $\times$ & $\times$ \\
\hline ice_density & $\rho_{i}$ & $x$ & $\times$ \\
\hline ice_softness & $A$ & & \\
\hline standard_gravity & $g$ & $x$ & $x$ \\
\hline till_c_o & $c_{0}$ & $\times$ & $\times$ \\
\hline till_compressibility_coefficient & $C_{\mathrm{c}}$ & $\times$ & $\times$ \\
\hline till_effective_fraction_overburden & $\delta$ & $x$ & $x$ \\
\hline till_reference_effective_pressure & $N_{0}$ & $\times$ & $x$ \\
\hline till_reference_void_ratio & $e_{0}$ & $x$ & $x$ \\
\hline
\end{tabular}
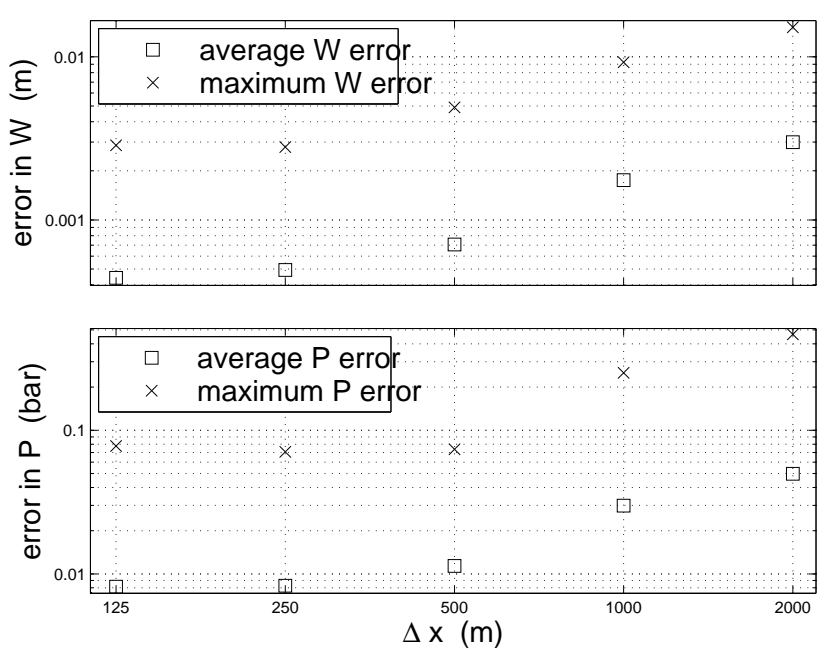

Figure 5. Average water thickness error $\left|W-W_{\text {exact }}\right|$ decays as $O\left(\Delta x^{0.91}\right)$, and average pressure error $\left|P-P_{\text {exact }}\right|$ decays as $O\left(\Delta x^{0.92}\right)$, for grids with spacing $250 \leq \Delta x=\Delta y \leq 2000 \mathrm{~m}$.

roughly linear (i.e., about $O\left(\Delta x^{1}\right)$ ) because the largest errors arise at locations of low regularity of the exact solution, including the radius $r=5 \mathrm{~km}$ where $P$ quickly drops from $P_{\mathrm{o}}$, and at the ice sheet margin where there is a jump in $W$ to 0 .

The rates of convergence for average errors are nearly identical for the higher-resolution flux-limited scheme and for the first-order upwinding scheme (not shown). Because our problem is an advection-diffusion problem in which both the advection velocity and the diffusivity are solution- dependent, it is difficult to separate the errors arising from numerical treatments of advection and diffusion. The firstorder upwinding scheme for the advection has much larger numerical diffusivity but this diffusivity is masked by the physical diffusivity. Based on our verification evidence it is reasonable to choose the simpler first-order upwind method for applications, as it requires less interprocess communication.

\subsection{Application to the Greenland ice sheet}

We now apply our hydrology models to the entire Greenland ice sheet at $2 \mathrm{~km}$ grid resolution. This nontrivial example demonstrates the model at large computational scale using real ice sheet geometry, with one-way coupling from ice dynamics giving realistic distributions of overburden pressure, ice sliding speed, and basal melt rate.

\subsubsection{Spun-up initial state}

The PISM dynamics and thermodynamics model (Bueler and Brown, 2009; Winkelmann et al., 2011; Aschwanden et al., 2012), using the non-mass-conserving null hydrology model (Sect. 6.6), was used to compute a consistent and nearly steady model of the ice sheet, a "spun-up" initial state, following the procedures in Aschwanden et al. (2013). Our model uses no spatially variable parameter values, such as basal shear stresses found by inversion of surface velocities. The bed elevations and present-day climate of the ice sheet, especially surface temperature and surface mass balance (Ettema et al., 2009), were from the Sea-level Response to Ice 

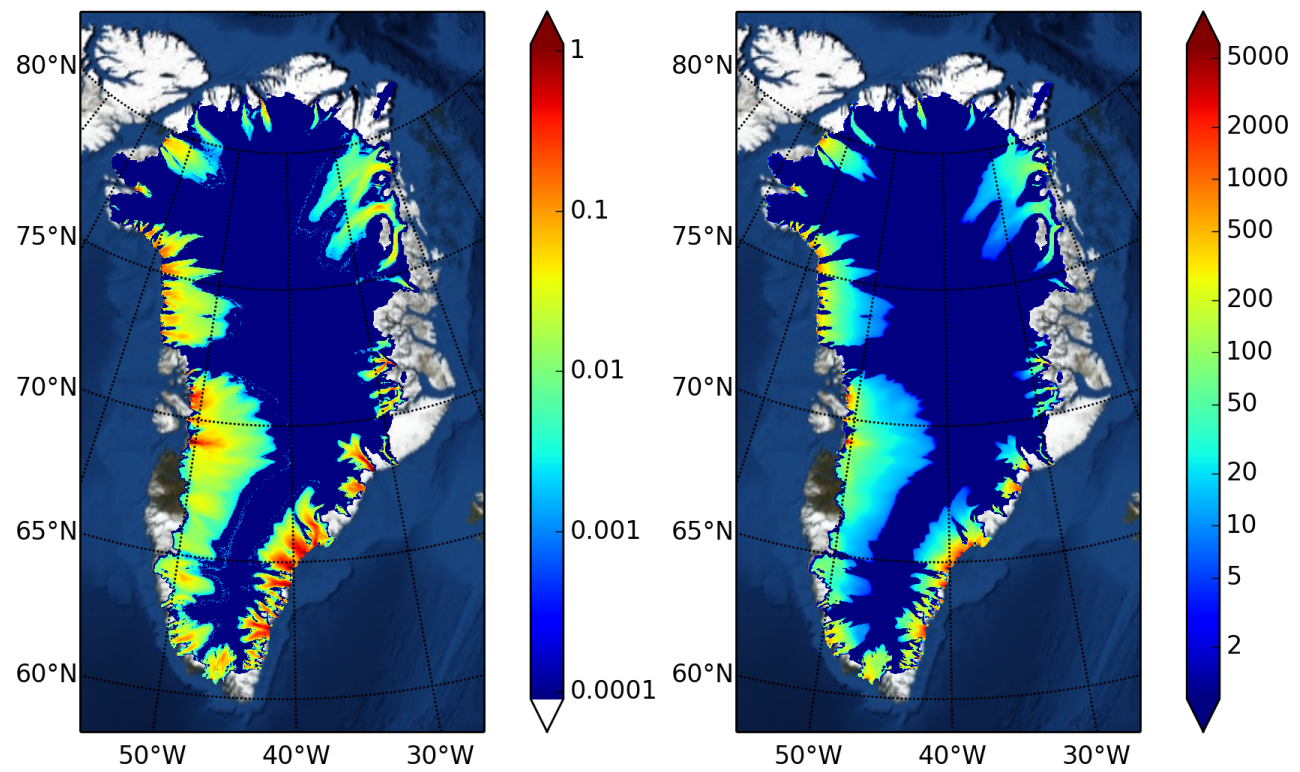

Figure 6. The inputs to the hydrology model are the modeled basal melt rate $m / \rho_{\mathrm{w}}\left(\right.$ left; $\left.\mathrm{ma}^{-1}\right)$ and sliding speed $\left|\boldsymbol{v}_{\mathrm{b}}\right|$ (right; $\mathrm{m}^{-1}$ ) from the spun-up state.

Sheet Evolution (SeaRISE) data set for Greenland (Bindschadler et al., 2013).

The spin-up grid sequence was to run $50 \mathrm{ka}$ on a $20 \mathrm{~km}$ grid, $20 \mathrm{ka}$ on a $10 \mathrm{~km}$ grid, $2 \mathrm{ka}$ on a $5 \mathrm{~km}$ grid, and finally $200 \mathrm{a}$ on a $2 \mathrm{~km}$ grid, with bilinear interpolation at each refinement stage. The final $2 \mathrm{~km}$ stage, on a horizontal grid of 1.05 million grid points, used uniform $10 \mathrm{~m}$ vertical spacing so that the ice sheet flow was modeled on a structured 3-D grid of 460 million velocity-temperature points. This whole spin-up used 2800 total processor hours on $722.2 \mathrm{GHz}$ AMD Opteron processors, a small computation for modern supercomputers.

The results of this spin-up were validated by comparing results to present-day observations. In the last $100 \mathrm{a}$ of this run the ice sheet volume varied by less than $0.04 \%$, so the model is in nearly steady state, though the actual Greenland ice sheet may not be as close to steady. The spun-up ice sheet volume of $3.094 \times 10^{6} \mathrm{~km}^{3}$ is close to the present-day volume of $3.088 \times 10^{6} \mathrm{~km}^{3}$ computed from the SeaRISE data on the same grid. Compared to volume alone, a better evaluation of dynamical quality is to compare the modeled and observed (Joughin et al., 2010) surface speed, with a very similar result to the comparison described in Aschwanden et al. (2013).

The spun-up initial state includes, in particular, modeled ice thickness $H$, basal melt rate $m$, and sliding velocity $\left|\boldsymbol{v}_{\mathrm{b}}\right|$; the latter two fields are shown in Figure 6. Areas of sliding roughly coincide with areas of basal melt because heatproducing (modeled) basal drag comes from the yield stress parameterized in Sect. 3.

\subsubsection{Experimental setup and model runs}

We used fields $H, m,\left|\boldsymbol{v}_{\mathrm{b}}\right|$ from the spun-up state as steady data in 5 model-year runs of the routing and distributed hydrology models; see Sect. 6.6 for model descriptions. Thus, only one-way coupling was tested: a steady ice dynamics model fed its fields to an evolving subglacial hydrology model. The hydrology model was initialized with the $W_{\text {til }}$ values from the spun-up state, but with $W=0$ initial values for both models, and also $P=0$ initial values for distributed.

In the runs, variables $W, W_{\text {til }}$, and $P$ were recomputed at each time step, at each of 1.05 million subglacial hydrology grid points, using parameter values from Table 1. In both rout ing and distributed models the hydrological system became steady after the first 3 model years.

Adaptively determined time steps reached a steady level of about 4 model hours for the routing model based on maximum subglacial water speeds $|\boldsymbol{V}|$ of $0.05 \mathrm{~m} \mathrm{~s}^{-1}$ and maximum diffusivity $D$ of $10.6 \mathrm{~m}^{2} \mathrm{~s}^{-1}$. For the distributed model the time steps were actually slightly longer, primarily because routing concentrates large water amounts and fluxes along steepest-descent paths; the time steps were about 6 model hours based on maximum speeds $|\boldsymbol{V}|$ of $0.03 \mathrm{~m} \mathrm{~s}^{-1}$ and much smaller maximum diffusivities $D$ of about $0.25 \mathrm{~m}^{2} \mathrm{~s}^{-1}$. These hydrology-only runs used much less computation than the spin-up: 14.7 processor hours for the routing run and 14.2 for distributed. 

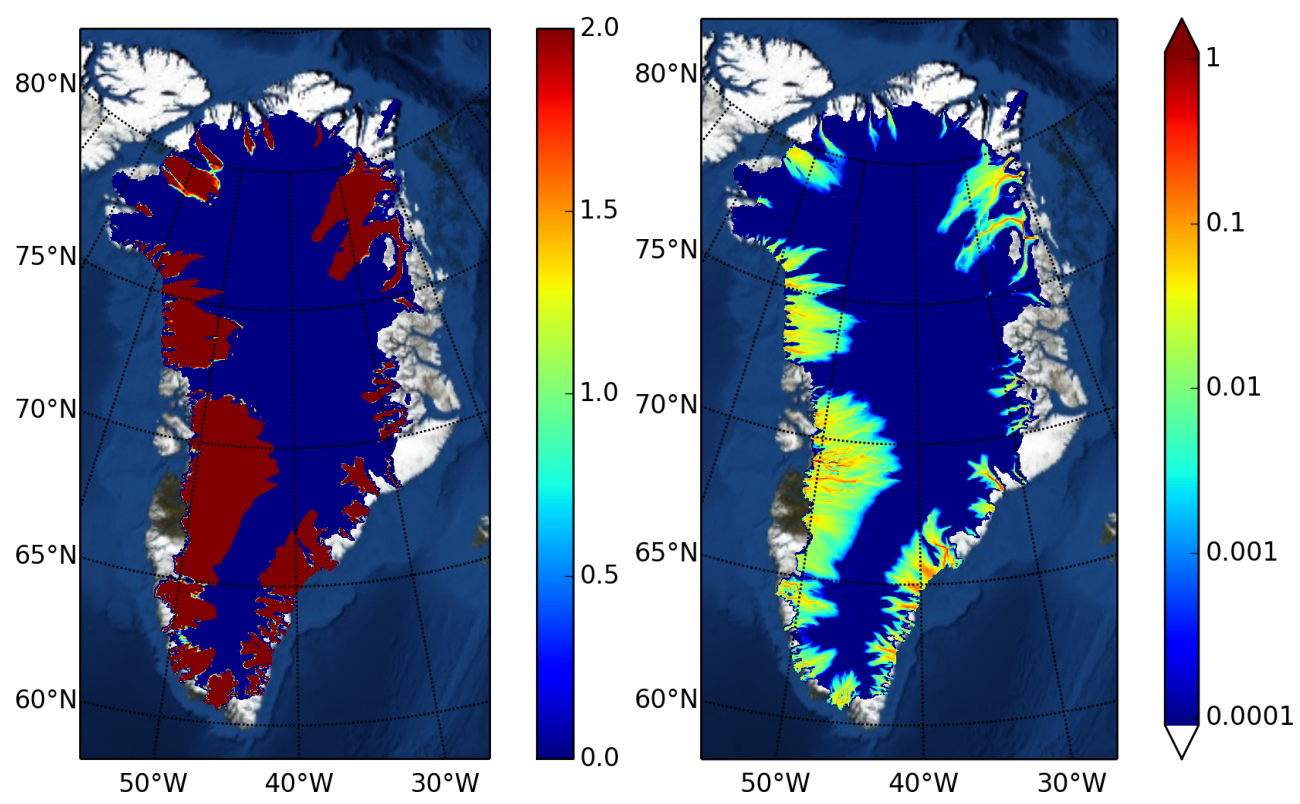

Figure 7. Outputs from the rout ing hydrology model are the modeled till-stored water layer thickness $W_{\text {til }}$ (left; m) and modeled transportable water layer thickness $W$ (right; $\mathrm{m}$ ).

\subsection{3 routing results}

The final $W_{\text {til }}$ and $W$ fields from the rout ing run are shown in Fig. 7. The till is fully saturated $\left(W_{\text {til }}=2 \mathrm{~m}\right)$ in essentially all areas where basal melt occurs. In the outlet glacier areas the transportable water $W$ concentrates along curves of steepest descent of the hydraulic potential; see detail in Fig. 8. The location of the pathways is determined primarily by the bedrock elevation detail provided by the SeaRISE data set, which is limited. Furthermore, the grid resolution of $2 \mathrm{~km}$, while very high for whole ice sheet models, still causes spatial "smearing" of the flow pathways.

The continuum limit of the model would have concentrated pathways of a few meters to tens of meters width. These concentrated pathways could be regarded as minimal "conduit-like" features of the subglacial hydrology. As noted in the introduction, however, our model has no "R-channel" conduit mechanism, in which dissipation heating of the flowing water generates wall melt back.

\subsection{4 distributed results}

The final values of $W$ and the relative water pressure $P / P_{\mathrm{o}}$ for the 5 model-year distributed run are shown in Fig. 9. The till is full $\left(W_{\text {til }}=2 \mathrm{~m}\right)$ in essentially all areas where basal melt occurs, so, as $W_{\text {til }}$ is nearly identical to the routing result, it is not shown.

Recall that $\left|\boldsymbol{v}_{\mathrm{b}}\right|$ determines the pressure drop caused by sliding-generated cavities. The effect is to spread out the water $W$ relative to the routing model, as clearly seen in Fig. 9. There is now no strong concentration of $W$ along curves of steepest descent of the hydraulic potential, but the

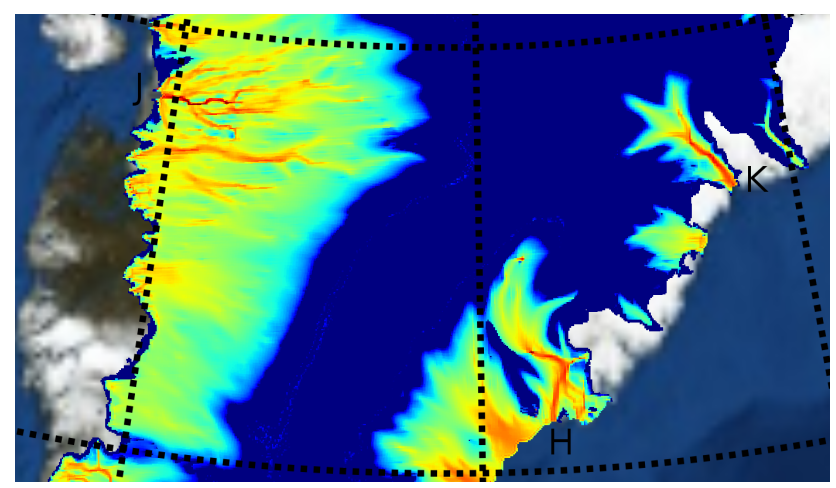

Figure 8. Detail of transportable water $W$ plotted in Fig. 7, covering Jakobshavn (J), Helheim (H), and Kangerdlugssuaq (K) outlet glaciers.

spreading depends on opening and closing parameters in the distributed model, especially parameters $c_{1}, c_{2}, \phi_{0}, W_{\mathrm{r}}$. Darcy flux model parameters $\alpha, \beta, k$ are also important. Parameter identification using observed surface, in situ, basal reflectivity, discharge, and other data, though needed, is beyond the scope of this paper.

We can examine the local relationship between water layer thickness $W$ and pressure $P$ in the distributed results. Though the model is near steady state, the basal melt rate, sliding speed, and overburden pressure all show realistically large spatial variations. In Fig. 10 we "bin" pairs $(W, P)$ by relatively narrow sliding speed ranges (each sub-plot) and color the points by the ice thickness. There is an increasing relationship between $W$ and the relative pressure $P / P_{\mathrm{o}}$ 

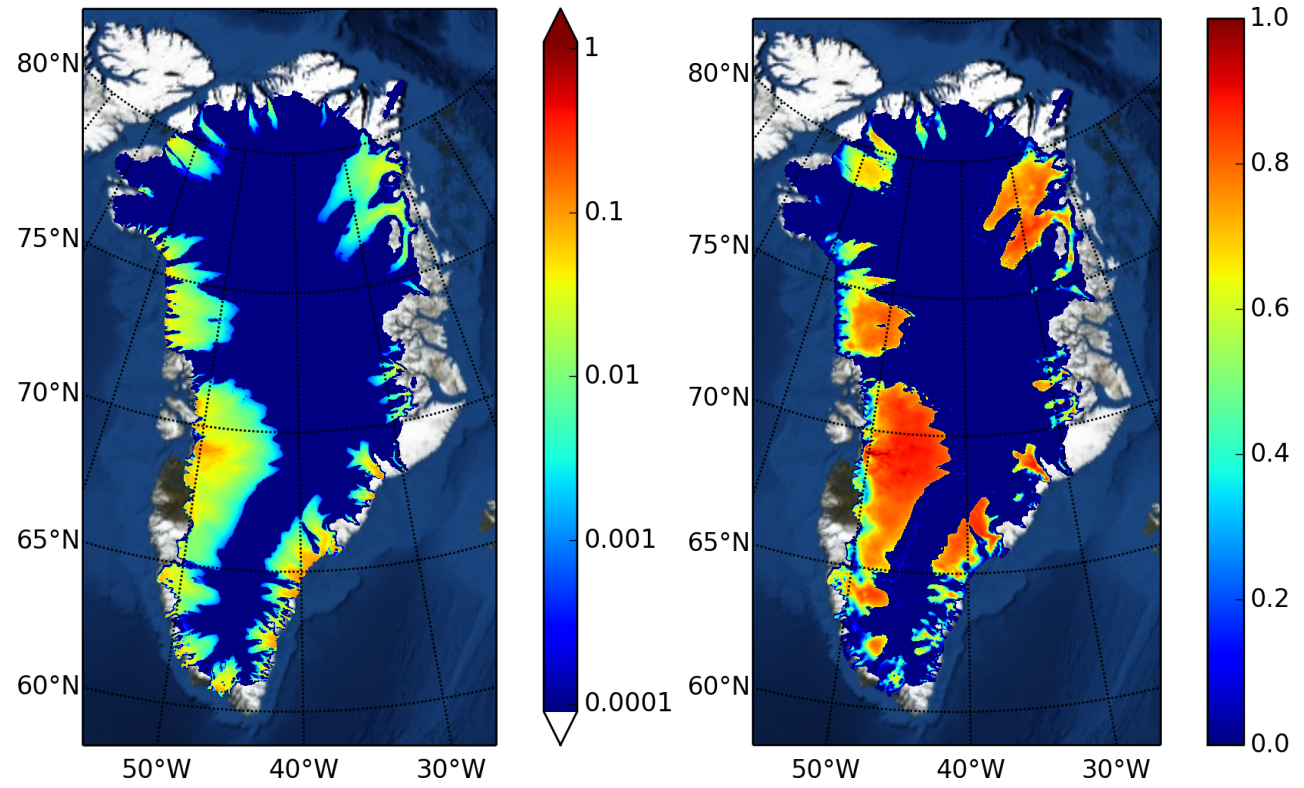

Figure 9. Outputs from the distributed hydrology model include the modeled transportable water layer thickness $W$ (left; $\mathrm{m}$ ), and the modeled transportable water layer pressure $P$, shown relative to overburden pressure (i.e., $P / P_{\mathrm{o}}$; right).
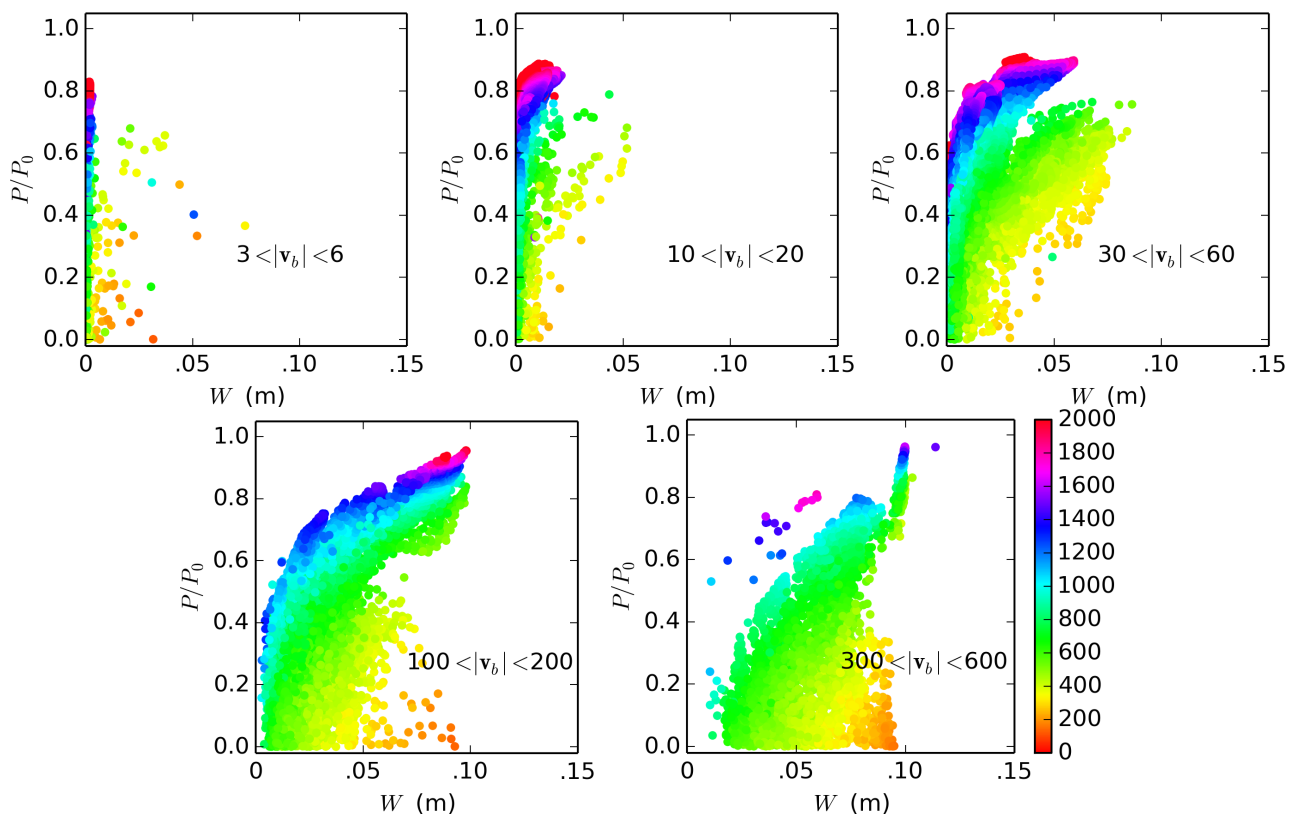

Figure 10. Scatter plots of $\left(W, P / P_{\mathrm{o}}\right)$ pairs for all cells from the distributed model run, which used roughness scale $W_{\mathrm{r}}=0.1 \mathrm{~m}$. Each sub-plot only shows pairs from the indicated range of ice sliding speeds. Points are colored by ice thickness using a common scale shown beside last figure.

in each bin. While in the fast-sliding case $W$ is often comparable to the bed roughness scale $W_{\mathrm{r}}$, for slow sliding we see generally lower water amounts $\left(W \lesssim W_{\mathrm{r}} / 10\right)$ but a full range of pressures. In thick ice the pressure $P$ is close to overburden even if there is fast sliding. Locations with high sliding, high water amount, and low pressure always have low ice thickness. 


\section{Conclusions}

This paper documents additions made to the Parallel Ice Sheet Model (PISM) in its 0.6 version released February 2014. It describes and demonstrates a subglacial hydrology model which is novel in having these features:

- a 2-D parallel implementation of a coupled till-andlinked-cavities model;

- a pressure-equation regularization, using notional englacial porosity, which eases implementation and improves numerical performance;

- a scheme for maintaining physical pressure bounds $(0 \leq$ $P \leq P_{\mathrm{o}}$ ) at all times;

- verification using a nearly exact solution of the coupled mass-conservation and pressure equations, in the steady radial case;
- demonstration at high resolution and whole ice-sheet scale on a million-point hydrology grid.

Furthermore, the comprehensive exposition here clarifies the relationship among several pressure-determining "closures" (Sect. 4), and it allows us to understand our model as a common extension of several seemingly disparate published models (Sect. 5). Additional analysis (Appendix A) shows that in steady state a functional relationship " $P=P(W)$ " arises between pressure and water layer thickness. This analysis reveals the diffusive nature of the apparently advective part of the steady-state flux.

The current paper only demonstrates one-way coupling, in which the PISM ice flow and thermodynamics model feeds basal melt rate and sliding velocities to the hydrology model. Two-way coupling will appear in future work. 


\section{Appendix A: Analysis of steady states}

Relative to the time-dependent model Eqs. (32), steady-state Eqs. (35)-(38) have separate balances between the divergence of the flux and the water input, and the opening and closing processes. In particular, Eq. (38) allows us to write the pressure $P=P(W)$ in steady state as a continuous function of the layer thickness $W$. However, steady state is only possible if a condition holds:

$c_{1}\left|\boldsymbol{v}_{\mathrm{b}}\right|\left(W_{\mathrm{r}}-W\right)_{+} \leq c_{2} A P_{\mathrm{o}}^{3} W$.

This condition says that the maximum closing rate $\mathcal{C}(N, W)$, which occurs at 0 water pressure, must equal or exceed the sliding-generated opening rate $\mathcal{O}\left(\left|\boldsymbol{v}_{\mathrm{b}}\right|, W\right)$.

We define a scaled basal sliding speed which has units of pressure; it is a scale for the pressure drop from cavitation:

$s_{\mathrm{b}}=\left(\frac{c_{1}\left|\boldsymbol{v}_{\mathrm{b}}\right|}{c_{2} A}\right)^{\frac{1}{3}}$.

Then Eq. (A1) is equivalent to the condition $W \geq W_{\mathrm{c}}$, where $W_{\mathrm{c}}=\frac{W_{\mathrm{r}} s_{\mathrm{b}}^{3}}{\left(s_{\mathrm{b}}^{3}+P_{\mathrm{o}}^{3}\right)}$ is a critical water thickness. If $W \geq W_{\mathrm{c}}$ then

$P(W)=P_{\mathrm{o}}-s_{\mathrm{b}}\left(\frac{\left(W_{\mathrm{r}}-W\right)_{+}}{W}\right)^{\frac{1}{3}}$.

Formula Eq. (A3) applies even if $W \geq W_{\mathrm{r}}$, in which case $P=$ $P_{\mathrm{o}}$. Under pressure $(P=0)$ with subcritical water amount $\left(W<W_{\mathrm{c}}\right.$ ) does not occur in steady state, though it can occur in non-steady conditions; note $P\left(W_{\mathrm{c}}\right)=0$. Figure A1 shows the function $P(W)$ for different values of sliding speed $\left|\boldsymbol{v}_{\mathrm{b}}\right|$, and Fig. A2 shows it for different values of overburden pressure $P_{\mathrm{o}}$.

Flowers and Clarke (2002a) proposed function $P_{\mathrm{FC}}(W)-$ see Eq. (28) - for both steady and non-steady circumstances. Both functions $P(W)$ and $P_{\mathrm{FC}}(W)$ are increasing, and both relate $P$ to the overburden pressure $P_{0}$. However, in Eq. (A3) the relation of $P$ to $P_{\mathrm{o}}$ is additive, while in Eq. (28) they are proportional. Power-law form Eq. (28) is not justified by the physical reasoning which led to Eq. (A3), even in steady state. It would appear that any functional relationship $P(W)$ should also depend on the sliding velocity, as it does here, if cavitation influences the water pressure. In any case, in the current paper we do not impose a relationship $P=P(W)$ at all, though such a relation emerges in steady state.

We now consider how the steady-state water velocity $\boldsymbol{V}$, and the associated flux $\boldsymbol{q}$, depends on other quantities. First, from Eqs. (35) and (A3), in steady state we have

$\frac{\partial P}{\partial W}=\frac{s_{\mathrm{b}} W_{\mathrm{r}}}{3 W^{\frac{4}{3}}\left(W_{\mathrm{r}}-W\right)^{\frac{2}{3}}}$

if $W_{\mathrm{c}}<W<W_{\mathrm{r}}$. If $W \leq W_{\mathrm{c}}$ then $\partial P / \partial W$ is undefined, and if $W>W_{\mathrm{r}}$ then $\partial P / \partial W=0$. Formula Eq. (A4) and Figs. A1 and $\mathrm{A} 2$ agree that $\frac{\partial P}{\partial W} \rightarrow \infty$ as $W \nearrow W_{\mathrm{r}}$.

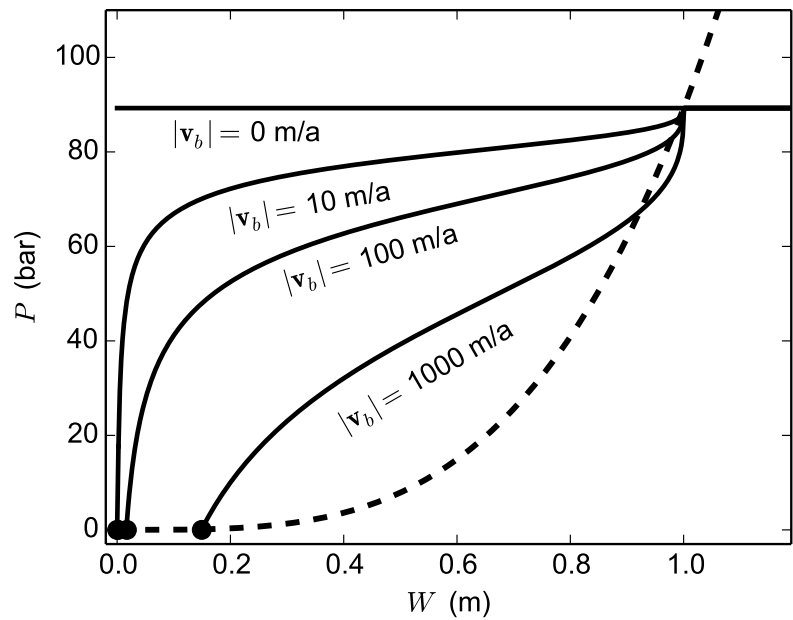

Figure A1. The steady-state function $P(W)$ defined by Eq. (A3), using $W_{\mathrm{r}}=1 \mathrm{~m}$ and $H=1000 \mathrm{~m}$ (solid curves). Values of $W_{\mathrm{c}}$ are indicated by black dots at $P=0$. For comparison, Flowers and Clarke (2002a) relation Eq. (28) is shown with $W_{\text {crit }}=1 \mathrm{~m}$ (dashed black).

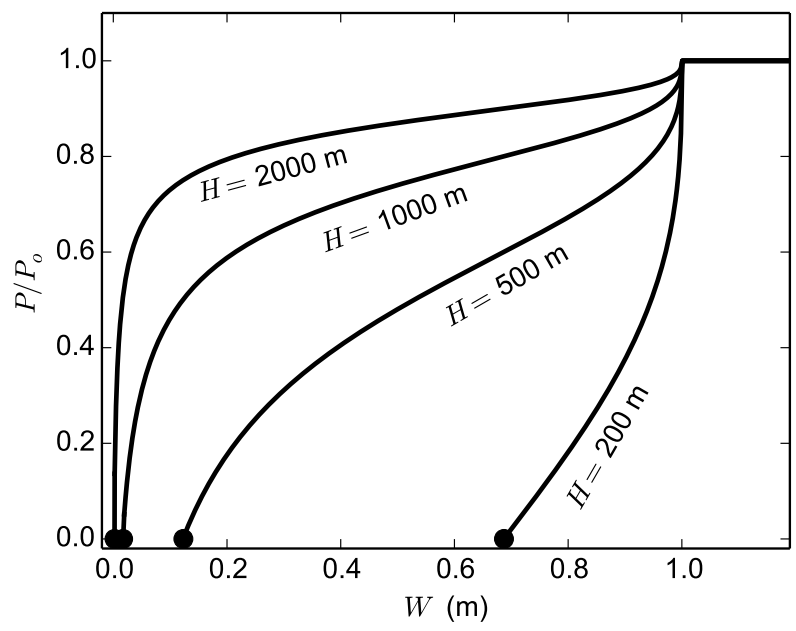

Figure A2. The graph of $P(W)$ defined by Eq. (A3) also depends on overburden pressure $P_{\mathrm{O}}=\rho_{i} g H$, shown using $\left|\boldsymbol{v}_{\mathrm{b}}\right|=100 \mathrm{~m} / \mathrm{a}$ and $W_{\mathrm{r}}=1 \mathrm{~m}$.

Now note that Eqs. (35), (A3), and (A4) imply a formula for the velocity in steady state:

$$
\begin{aligned}
\boldsymbol{V} & =-k\left[\nabla \psi_{o}-\left(\frac{W_{\mathrm{r}}-W}{W}\right)^{\frac{1}{3}} \nabla s_{\mathrm{b}}\right. \\
& \left.+\frac{s_{\mathrm{b}} W_{\mathrm{r}}}{3 W^{\frac{4}{3}}\left(W_{\mathrm{r}}-W\right)^{2 / 3}} \nabla W\right],
\end{aligned}
$$

where $\psi_{o}=P_{\mathrm{o}}+\rho_{\mathrm{w}} g b$. Thus, the direction of water velocity $\boldsymbol{V}$ is determined by a combination of a geometric direction $\left(\nabla \psi_{o}\right)$, a direction derived from spatial variations in the sliding speed $\left(\nabla s_{\mathrm{b}}\right)$, and a diffusive direction $(\nabla W)$. Indeed, a portion of the advective flux $\boldsymbol{V} W$ is diffusive in steady 
state, in addition to the a priori diffusive flux $-D \nabla W$; recall Eq. (11) in Sect. 2.4. In fact, because the coefficient of $\nabla W$ in Eq. (A5) remains large when $W \rightarrow 0$, as long as sliding is occurring $\left(s_{\mathrm{b}}>0\right)$, then for low water amount and sustained sliding we should think of the water as diffusing in the layer. On the other hand, when the water thickness is almost at the roughness scale $\left(W \lesssim W_{\mathrm{r}}\right)$, then the same coefficient is also large in sliding cases $\left(s_{\mathrm{b}}>0\right)$; again the effect is diffusive. 


\section{Code availability}

The source code for all versions of PISM is available through host website https://github.com/pism/pism. Extensive PDF and searchable browser documentation for PISM is contained both in the source code and online through the PISM website http://www.pism-docs.org/. PISM is licensed under the GNU General Public License (version 3).

Acknowledgements. Comments by editor Dan Goldberg, reviewer Tim Bartholomaus, and two anonymous reviewers improved the focus and quality of the paper. Detailed comments by Andy Aschwanden and Martin Truffer were much appreciated. Constantine Khroulev helped with the PISM implementation. The first author was supported by NASA grant \#NNX13AM16G. This work was supported by a grant of high-performance computing resources from the Arctic Region Supercomputing Center.

Edited by: D. Goldberg

\section{References}

Andrews, L. C., Catania, G. A., Hoffman, M. J., Gulley, J. D., Lüthi, M. P., Ryser, C. , Hawley, R. L., and Neumann, T. A.: Direct observations of evolving subglacial drainage beneath the Greenland Ice Sheet, Nature, 514, 80-83, doi:10.1038/nature13796, 2014.

Ascher, U. and Petzold, L.: Computer Methods for Ordinary Differential Equations and Differential-algebraic Equations, SIAM Press, Philadelphia, PA, 1998.

Aschwanden, A., Bueler, E., Khroulev, C., and Blatter, H.: An enthalpy formulation for glaciers and ice sheets, J. Glaciol., 58, 441-457, doi:10.3189/2012JoG11J088, 2012.

Aschwanden, A., Aðalgeirsdóttir, G., and Khroulev, C.: Hindcasting to measure ice sheet model sensitivity to initial states, The Cryosphere, 7, 1083-1093, doi:10.5194/tc-7-1083-2013, 2013.

Balay, S., Abhyankar, S., Adams, M., Brown, J., Brune, P., Buschelman, K., Eijkhout, V., Gropp, W., Kaushik, D., Knepley, M., Curfman McInnes, L., Rupp, K., Smith, B., and Zhang, H.: PETSc Users Manual, Tech. Rep. ANL-95/11 - Revision 3.2, Argonne National Laboratory, 2011.

Bartholomaus, T. C., Anderson, R. S., and Anderson, S. P.: Response of glacier basal motion to transient water storage, Nature Geosci., 1, 33-37, doi:10.1038/ngeo.2007.52, 2008.

Bartholomaus, T. C., Anderson, R. S., and Anderson, S. P.: Growth and collapse of the distributed subglacial hydrologic system of Kennicott Glacier, Alaska, USA, and its effects on basal motion, J. Glaciol., 57, 985-1002, 2011.

Bindschadler, R., Nowicki, S., Abe-Ouchi, A., Aschwanden, A., Choi, H., Fastook, J., Granzow, G., Greve, R., Gutowski, G., Herzfeld, U., Jackson, C., Johnson, J., Khroulev, C., Levermann, A., Lipscomb, W. H., Martin, M. A., Morlighem, M., Parizek, B. R., Pollard, D., Price, S. F., Ren, D., Saito, F., Sato, T., Seddik, H., Seroussi, H., Takahashi, K., Walker, R., and Wang, W. L.: Icesheet model sensitivities to environmental forcing and their use in projecting future sea-level (The SeaRISE Project), J. Glaciol, 59, 195-224, 2013.
Bueler, E.: Correspondence: Extensions of the lumped subglacialenglacial hydrology model of Bartholomaus, et al. (2011), submitted to J. Glaciol., 2014.

Bueler, E. and Brown, J.: Shallow shelf approximation as a "sliding law" in a thermodynamically coupled ice sheet model, J. Geophys. Res., 114, f03008, doi:10.1029/2008JF001179, 2009.

Bueler, E., Lingle, C. S., Kallen-Brown, J. A., Covey, D. N., and Bowman, L. N.: Exact solutions and numerical verification for isothermal ice sheets, J. Glaciol., 51, 291-306, 2005.

Clarke, G. K.: Hydraulics of subglacial outburst floods: new insights from the Spring-Hutter formulation, J. Glaciol., 49, 299-313, doi:10.3189/172756503781830728, 2003.

Clarke, G. K. C.: Subglacial processes, Annu. Rev. Earth Planet. Sci., 33, 247-276, doi:10.1146/annurev.earth.33.092203.122621, 2005.

Creyts, T. and Schoof, C.: Drainage through subglacial water sheets, J. Geophys. Res., 114, doi:10.1029/2008JF001215, 2009.

Cuffey, K. M. and Paterson, W. S. B.: The Physics of Glaciers, Elsevier, 4th edn., Burlington, MA, USA, 2010.

Das, S. B., Joughin, I., Behn, M. D., Howat, I. M., King, M. A., Lizarralde, D., and Bhatia, M. P.: Fracture Propagation to the Base of the Greenland Ice Sheet During Supraglacial Lake Drainage, Science, 320, 778-781, doi:10.1126/science.1153360, 2008.

de Fleurian, B., Gagliardini, O., Zwinger, T., Durand, G., Le Meur, E., Mair, D., and Råback, P.: A double continuum hydrological model for glacier applications, The Cryosphere, 8, 137-153, doi:10.5194/tc-8-137-2014, 2014.

Ettema J., van den Broeke, M. R., van Meijgaard, E., van de Berg, W. J., Bamber, J. L., Box, J. E., and Bales, R. C.: Higher surface mass balance of the Greenland ice sheet revealed by highresolution climate modeling, Geophys. Res. Lett., 36, L12501, doi:10.1029/2009GL038110, 2009.

Flowers, G. E. and Clarke, G. K. C.: A multicomponent coupled model of glacier hydrology 1 . Theory and synthetic examples, J. Geophys. Res., 107, 2287, doi:10.1029/2001JB001122, 2002a.

Flowers, G. E. and Clarke, G. K. C.: A multicomponent coupled model of glacier hydrology 2. Application to Trapridge Glacier, Yukon, Canada, J. Geophys. Res., 107, 2288 , doi:10.1029/2001JB001124, 2002b.

Fountain, A., Jacobel, R. W., Schlichting, R., and Jansson, P.: Fractures as the main pathways of water flow in temperate glaciers, Nature 433, 618-621, doi:doi:10.1038/nature03296, 2005.

Goeller, S.: Antarctic Subglacial Hydrology: Interactions of subglacial lakes, basal water flow, and ice dynamics, PhD Dissertation, Universität Bremen, 2014.

Goeller, S., Thoma, M., Grosfeld, K., and Miller, H.: A balanced water layer concept for subglacial hydrology in large-scale ice sheet models, The Cryosphere, 7, 1095-1106, doi:10.5194/tc-71095-2013, 2013.

Greve, R. and Blatter, H.: Dynamics of Ice Sheets and Glaciers, Advances in Geophysical and Environmental Mechanics and Mathematics, Springer, Berlin, Germany, 2009.

Harper, J., Bradford, J., Humphrey, N., and Meierbachtol, T.: Vertical extension of the subglacial drainage system into basal crevasses, Nature, 467, 579-582, doi:10.1038/nature09398, 2010.

Hewitt, I. J.: Modelling distributed and channelized subglacial drainage: the spacing of channels, J. Glaciol., 57, 302-314, 2011. 
Hewitt, I. J.: Seasonal changes in ice sheet motion due to melt water lubrication, Earth Planet. Sci. Lett., 371-372, 16-25, doi:10.1016/j.eps1.2013.04.022, 2013.

Hewitt, I. J., Schoof, C., and Werder, M. A.: Flotation and free surface flow in a model for subglacial drainage. Part II: Channel flow, J. Fluid Mech., 702, 157-188, 2012.

Hoffman, M. J. and Price, S.: Feedbacks between coupled subglacial hydrology and glacier dynamics, J. Geophys. Res. Earth Surf., 119, 414-436, doi:10.1002/2013JF002943, 2014.

Hooke, R., Hanson, B., Iverson, N. R., Jansson, P., and Fischer, U. H.: Rheology of till beneath Störglaciaren, Sweden, J. Glaciol., 43, 172-179, 1997.

Hundsdorfer, W. and Verwer, J. G.: Numerical Solution of TimeDependent Advection-Diffusion-Reaction Equations, Springer Series in Computational Mathematics, Springer, Berlin, Germany, 2003.

Huybrechts, P., Payne, T., and The EISMINT Intercomparison Group: The EISMINT benchmarks for testing ice-sheet models, Ann. Glaciol., 23, 1-12, 1996.

Johnson, J. and Fastook, J. L.: Northern Hemisphere glaciation and its sensitivity to basal melt water, Quat. Int., 95, 65-74, 2002.

Joughin, I., Smith, B. E., Howat, I. M., Scambos, T., and Moon, T.: Greenland flow variability from ice-sheet-wide velocity mapping, J. Glaciol., 56, 415-430, 2010.

Kamb, B.: Glacier surge mechanism based on linked cavity configuration of the basal water conduit system, J. Geophys. Res., 92, 9083-9100, 1987.

Kamb, B.: Rheological nonlinearity and flow instability in the deforming bed mechanism of ice stream motion, J. Geophys. Res.Sol. Ea., 96, 16585-16595, 1991.

Kinderlehrer, D. and Stampacchia, G.: An Introduction to Variational Inequalities and their Applications, Pure and Applied Mathematics, Academic Press, New York, USA, 1980.

Le Brocq, A., Payne, A., Siegert, M., and Alley, R.: A subglacial water-flow model for West Antarctica, J. Glaciol., 55, 879-888, doi:10.3189/002214309790152564, 2009.

LeVeque, R. J.: Finite Volume Methods for Hyperbolic Problems, Cambridge Texts in Applied Mathematics, Cambridge University Press, Cambridge, United Kingdom, 2002.

Lingle, C. S. and Brown, T. J.: A subglacial aquifer bed model and water pressure-dependent basal sliding relationship for a West Antarctic ice stream, in: Dynamics of the West Antarctic Ice Sheet, edited by: der Veen, C. J. V. and Oerlemans, J., D. Reidel, Dodrecht, the Netherlands, 1987.

Livingstone, S. J., Clark, C. D., Woodward, J., and Kingslake, J.: Potential subglacial lake locations and meltwater drainage pathways beneath the Antarctic and Greenland ice sheets, The Cryosphere, 7, 1721-1740, doi:10.5194/tc-7-1721-2013, 2013.

Mahaffy, M. W.: A three-dimensional numerical model of ice sheets: tests on the Barnes Ice Cap, Northwest Territories, J. Geophys. Res., 81, 1059-1066, 1976.

Martin, M. A., Winkelmann, R., Haseloff, M., Albrecht, T., Bueler, E., Khroulev, C., and Levermann, A.: The Potsdam Parallel Ice Sheet Model (PISM-PIK) - Part 2: Dynamic equilibrium simulation of the Antarctic ice sheet, The Cryosphere, 5, 727-740, doi:10.5194/tc-5-727-2011, 2011.

Morton, K. W. and Mayers, D. F.: Numerical Solutions of Partial Differential Equations: An Introduction, Cambridge University Press, 2nd edn., Cambridge, United Kingdom, 2005.
Nye, J. F.: Water flow in glaciers: Jökulhlaups, tunnels and veins, J. Glaciol., 17, 181-207, 1976.

PISM authors: PISM, a Parallel Ice Sheet Model: User's Manual, http://www.pism-docs.org, last access: 12 May 2015.

Rooney, S. T., Blankenship, D. D., Alley, R. B., and Bentley, C. R.: Till beneath ice stream B: 2. structure and continuity, J. Geophys. Res.-Sol. Ea., 92, 8913-8920, 1987.

Schoof, C.: The effect of cavitation on glacier sliding, P. R. Soc. A, 461, 609-627, doi:10.1098/rspa.2004.1350, 2005.

Schoof, C.: A variational approach to ice stream flow, J. Fluid Mech., 556, 227-251, 2006a.

Schoof, C.: Variational methods for glacier flow over plastic till, J. Fluid Mech., 555, 299-320, 2006b.

Schoof, C.: Cavitation on deformable glacier beds, SIAM J. Appl. Math., 67, 1633-1653, 2007.

Schoof, C.: Coulomb friction and other sliding laws in a higher order glacier flow model, Math. Models Methods Appl. Sci. (M3AS), 20, 157-189, doi:10.1142/S0218202510004180, 2010a.

Schoof, C.: Ice sheet acceleration driven by melt supply variability, Nature, 468, 803-806, 2010b.

Schoof, C., Hewitt, I. J., and Werder, M. A.: Flotation and free surface flow in a model for subglacial drainage. Part I: Distributed drainage, J. Fluid Mech., 702, 126-156, 2012.

Shreve, R.: Movement of water in glaciers, J. Glaciol, 11, 205-214, 1972.

Siegert, M., Le Brocq, A., and Payne, A.: Hydrological connections between Antarctic subglacial lakes, the flow of water beneath the East Antarctic Ice Sheet and implications for sedimentary processes, in: Glacial Sedimentary Processes and Products, edited by: Hambrey, M. J., Christoffersen, P., Glasser, N. F., and Hubbard, B., 3-10, Wiley-Blackwell, Malden, MA, USA, 2007.

Truffer, M. and Harrison, W.: In situ measurements of till deformation and water pressure, J. Glaciol., 52, 175-182, 2006.

Truffer, M., Echelmeyer, K., and Harrison, W.: Glacier motion dominated by processes deep in underlying till, J. Glaciol., 46, 213221, 2000.

Truffer, M., Echelmeyer, K., and Harrison, W.: Implications of till deformation on glacier dynamics, J. Glaciol., 47, 123-134, doi:10.3189/172756501781832449, 2001.

Tulaczyk, S., Kamb, W. B., and Engelhardt, H. F.: Basal mechanics of Ice Stream B, West Antarctica 1. Till mechanics, J. Geophys. Res., 105, 463-481, 2000a.

Tulaczyk, S., Kamb, W. B., and Engelhardt, H. F.: Basal mechanics of Ice Stream B, West Antarctica 2. Undrained plastic bed model, J. Geophys. Res., 105, 483-494, 2000 b.

Van der Wel, N., Christoffersen, P., and Bougamont, M.: The influence of subglacial hydrology on the flow of Kamb Ice Stream, West Antarctica, J. Geophys. Res.-Earth, 118, 1-14, doi:10.1029/2012JF002570, 2013.

Van Pelt, W.: Modelling the dynamics and boundary processes of Svalbard glaciers, PhD thesis, Institute for Marine and Atmospheric Research Utrecht (IMAU), The Netherlands, 2013.

Vázquez, J. L.: The Porous Medium Equation, Oxford Mathematical Monographs, The Clarendon Press Oxford University Press, Oxford, 2007.

Walder, J. S.: Stability of sheet flow of water beneath temperate glaciers and implications for glacier surging, J. Glaciol., 28, 273 293, 1982. 
Werder, M., Hewitt, I., Schoof, C., and Flowers, G.: Modeling channelized and distributed subglacial drainage in two dimensions, $\mathbf{J}$ Geophys. Res.-Earth, 118, 2140-2158, 2013.

Wesseling, P.: Principles of Computational Fluid Dynamics, Springer-Verlag, Berlin, Germany, 2001.
Winkelmann, R., Martin, M. A., Haseloff, M., Albrecht, T., Bueler, E., Khroulev, C., and Levermann, A.: The Potsdam Parallel Ice Sheet Model (PISM-PIK) - Part 1: Model description, The Cryosphere, 5, 715-726, doi:10.5194/tc-5-715-2011, 2011. 